\title{
A common-sense approach to the problem of the itinerary stadion
}

\author{
Irina Tupikova ${ }^{1}$ (D)
}

Received: 28 May 2021 / Accepted: 27 January 2022 / Published online: 3 March 2022

(c) The Author(s) 2022

\begin{abstract}
Estimating the length of the Greek stadion remains controversial. This paper highlights the pitfalls of a purely metrological approach to this problem and proposes a formal differentiation between metrologically defined ancient measuring units and other measures used to estimate long distances. The common-sense approach to the problem is strengthened by some cross-over documentary evidence for usage of the so-called itinerary stadion in antiquity. We discuss the possibility of using statistical analysis methods to estimate the length of the stadion by comparing ancient routes with the actual distances. Simple numerical examples explain the limits of this approach, caused by the low number of data and by their mixed character. A special case of distances which can be calculated with the help of coordinates given in Ptolemy's Geography is discussed, and has been shown to lead unavoidably to ambiguous solutions.
\end{abstract}

\section{Introduction}

The vast amount of modern literature on the length of the Greek stadion is in severe contrast with the number of ancient sources concerning its definition, or making comparisons with the other ancient metrological units. Like other Mediterranean or Near Eastern measures, ${ }^{1}$ the Greek units were originally based on the lengths of human body parts. Their relatively wide variations were neglected and approximated by round figures to establish what was believed to be a practical scheme. Thus, according to Herodotus (2.149.3), a hundred ỏ $\rho \gamma v \iota$ ii/fathoms are equal to the $\sigma \tau \alpha$ ó $\delta$ เov/stadion of 600 feet; the fathom measures 6 feet or $\tau \varepsilon \tau \rho \alpha \pi \eta \dot{\eta} \chi \varepsilon 0 \varsigma /$ four cubits, the foot four spans

$\overline{1}$ Cf. Vitruvius 3.1.5; Heron 1.1; Polybius 2.157f.

Communicated by Jürgen Renn.

Irina Tupikova

Irina.Tupikova@tu-dresden.de

1 Lohrmann Observatory, TU Dresden, August-Bebel-Straße 30, 01219 Dresden, Germany 
and the cubit six spans. ${ }^{2}$ Once the small metrological units in this scheme (cubits or feet) have been standardized, one could construct a fixed metrological module with the corresponding gauges. The scheme given by Herodotus leads to the stadion of 400 cubits defined in a metrological way. The scholar had not specified which cubit or foot was meant here (although he was aware of other measures ${ }^{3}$ ) and thus became partly responsible for the diversity of the estimates of the length of the stadion throughout the history of science.

Of course, not all fields of human activity demand high standardization of measuring units: exact standards were obligatory in architecture but, for example, reduced precision could have been used to measure fields for the purpose of taxation. ${ }^{4}$ Somewhere within the procedure of handling long distances, measuring with a rod or rope would have been abandoned in favour of estimating the distances by counting steps or by recording travel time. As Herodotus (2.6) states, "Men that have scant land measure by orgyiai; those that have more, by stadia; those that have much land, by parasangs; and those who have great abundance of it, by schoeni". The step length cannot be directly read off a human body, but depends strongly upon its dimensions and can be approximately expressed through the other elements of a metrological module. For example, the 1000 passus (double pace or stride) of the Roman system of measures was equated to one Roman mile and the length of a double step to 5 Roman feet. The preserved sources on the Greek system do not contain information about an agreement for the length of the Greek step, ${ }^{5}$ but later Heron equates the step, $\beta \tilde{\eta} \mu \alpha$, to 2.5 feet $^{6}$ thus making a double step, exactly as in the Roman system, equal to 5 feet-with this relation, the stadion of 600 feet amounts to 240 steps. $^{7}$ Although related in this way to the ancient metrological modules, the step was never a precise gauge-simply because the length of a step never exactly measures 2.5 feet. The stadion measured with a rod marked in cubits or feet was a metrological unit, but the stadion counted as 240 steps was not. Measurements in steps could never have achieved the precision of measuring with a gauge; moreover, the measurement had different systematic errors

\footnotetext{
2 Hultsch (1882: 30 no. 13) remarks that the ancient authors preferred to give measures in whole numbers when switching between feet, cubits and fathoms (see, for example, Polybius 6.23; Herodotus 3.60).

3 "The royal cubit is greater by three fingers' breadth than the common cubit" (Herodotus 1.178) or "the Egyptian cubit is equal to the Samian cubit" (Herodotus 2.168). Herodotus (1.178) also gives the height and breadth of the Babylonian Wall in royal cubits explicitly differentiating them from the 'common' (Greek) cubits.

4 Although land surveying was quite developed in ancient Egypt and measuring ropes with knots tied at regular intervals of one cubit achieved the length of 100 cubits (Lepsius (1866: 5) was the first to state the existence of cubit rods and Badawy (1965: 42) assumed that such devices were in use from the time of the First Dynasty onwards), the areas of fields were approximated with simple geometrical figures and calculated with oversimplified algorithms. See, for example, problems 49 and 51 in the Rhind Mathematical Papyrus (ca.1550 BC) or the dedicatory inscription in the Temple of Horus at Edfu (ca. 100 BC).

5 See Hultsch (1882: 37): "Von Griechen findet sich der Schritt nirgends als eigentliches Maß erwähnt, obgleich es sicher ist, dass bei ihnen die Entfernungen zumeist nur durch Ausschreiten bestimmt worden sind".

${ }^{6}$ Hultsch (1864: 21-22, 180). See also Isidor Origenes 15.15 and Vitruvius 3.1.5. Julian of Askalon equates a step to three feet.

7 See Hultsch (1864: 186). As F. Hultsch (1882: 37) formulated: "Auf das Stadion sind ohne Zweifel 240 einfache oder 120 Doppelschritt gerechnet worden".
} 
depending on the terrain. Thus, the corresponding stadion was always different from its metrological value and we will refer to it as an 'itinerary' stadion. ${ }^{8}$

This is not the only reason why we cannot expect an unambiguous estimation of the length of the Greek stadion. Because a whole range of interrelated measuring modules was contemporaneously in use in antiquity, an attempt to calculate its length in relation to foreign units unavoidably led to a confusion. For example, according to Herodotus (2.6.3), a parasang measured 30 and a schoinos 60 stades $^{9}$, but Pliny the Elder in his Natural History (12.53) remarks that in Eratosthenes' calculations a schoinos was equal to 40 stades, "that is 5 miles", but adds that some authorities equate the schoinos to 32 stades. ${ }^{10}$ It is exactly this remark which-in combination with the scheme transmitted by Herodotus - gave rise to so many different metrological estimations of the length of Eratosthenes' stadion.

Starting from the Roman period, scholars have borrowed ancient Hellenistic distances and tried to interpret them in terms of conventional Roman miles-and the conversion coefficients were found to be different. How could they be the same when comparing distances measured (at least, partly) by the Romans, with the distances estimated by Greeks using striding? One can quote Strabo (7.7.4), who says that 'most' calculate eight stadia to the mile, but Polybius used a stadion that equalled $81 / 3$ stadia to the mile $\mathrm{e}^{11}$ and-in addition to this-for the via Appia between Rome and Aricia, with the length of 16 Roman miles, Strabo (5.3.12) calculates the route to be 160 stades, that is, with a ratio of $1: 10 .^{12}$

In this text, we aim to present-without advancing into the treacherous minefield of ancient metrology-some common-sense arguments concerning the length of the Greek stadion and its relation to the Roman mile. In our opinion, these considerations should underlie any attempt to estimate the length of the stadion, or should at least be kept in mind while considering the diversity of the existing figures. The questions we will pose, and try to answer, in this text are as follows:

1. How were long distances measured in antiquity?

2. Given that long distances were measured by striding, how can the length of the stadion and the Roman mile be estimated?

3. Where does the relation of 1: 8 between the stadion and the Roman mile come from?

\footnotetext{
8 The term 'itinerary stadion' was first introduced by Rennel (1800: 13-34).

9 Later, Heron expressly states that the schoinos and the parasang are equal (Bruins 1964: 175).

10 For the schoinos by Eratosthenes, see also Strabo (15.1.11) and the commentary of Berger (1880: 225, no 4) to Arrian's Indica. The same relation 1: 40 is used according to Strabo (11.14.11) by Theophanes.

11 The same ratio is mentioned by Censorinus (13.2). The metrological table of late antiquity attributed to Julian of Askalon calculates the Roman mile to be 8 1/4 of Eratosthenes' stadion, and this was amended to 8 $1 / 3$ by Diller (1949); but cf. Viedebantt (1915) for another interpretation of this ratio. The same metrological table also mentions that 'today' the equivalent is $71 \frac{1}{2}$ stadia (Edelstein and Kidd 2005: fr. 203). This ratio is attested by, among others, Heron (Geometrica 106.24) and Dio Cassius (38.17.7, 39.50.2, 46.44.4, etc.). Plutarch in the Life of Gaius Gracchus (28.7) mentioned that the Roman mile is "a little less than eight stades".

12 See Ideler (1826/1827: 127). The same ratio can be found in the Byzantine Scholia on Lucian (Rabe 1906). Many examples are discussed by d'Anville (1741: 15, 48, 57-63); Ideler 1826/1827: 1-12, 113-118, 126-127, Hultsch (1882: 59-60); Oxé (1926: 222); Lehmann-Haupt (1929:1934-1935); Meuret (1998: 151).
} 
4. Can this relation be reliably validated by the comparison of the lengths of ancient routes with modern data?

5. Do we have enough ancient data to determine the length of the stadion with statistical methods?

6. Can we use geographical coordinates given by Ptolemy in his Geography to statistically determine the length of the stadion?

Some of our arguments may look trivial to historians of science, and some are very simple to mathematicians; some are intuitively obvious; others are counter-intuitive. It is effectively straightforward practical arguments that will, we hope, enable a critical reader to draw his own conclusions.

\section{Striding or measuring?}

In determining the ancient measuring units, one should strictly distinguish between the measures used in architecture and those applied when estimating distances. Whereas the first discipline demanded firm metrological standards and a consistent metrological scheme, the measures applied in the surveying belonged to two different classes. Short distances could be measured with the help of a metrical gauge supporting the precision of the metrological standards. In contrast, long distances, and distances in mountainous regions, those along rivers or across an open sea could not be measured in antiquity with the help of a gauge and with similar precision. The measuring units used for such distances belonged to the class of 'fuzzy' measuring modules, with fuzzy relationships between their elements ${ }^{13}$ depending upon the personal qualities of a surveyor and upon the terrain. For simplicity, we can call such measures 'itinerary units'. The correlation between a metrological and an itinerary system of measures cannot be defined unambiguously and an eclectic approach can produce problematic results.

The issue with the length of the schoinos highlights in many respects the general problem of treating a (possibly) itinerary measuring unit as an element of a metrological system. That the schoinos was an Egyptian itinerary measure is now widely accepted. It has been established that it was identical to the technical term jtrw/iteru (Brugsch 1867; Schlott-Schwab 1981: 113) which represented initially the distance over which a towing team was able to tow a boat without a pause and is generally agreed upon to correspond approximately to $10.5 \mathrm{~km}$ or one hour in time-units (Jansen-Winkeln 2006; Radt 2002: 8.448; Chaumont 1984: 66-67). If so, the lengths of the routes along the river corresponding to the same number of schoini were different for different parts or stages of the river (consider, for example, the Cataracts of the Nile). This can partly explain why_according to Strabo (17.1.24) — the length of the schoinos varied between 30 and 120 stades in different areas along the Nile.

It is worth remembering how the estimation of iteru as $10.5 \mathrm{~km}$ first appeared in the scientific literature. In 1903, V. Loret proposed the following approach: The famous Ptolemaic inscriptions describe the land south of Elephantine as the 'land of 12 iteru'.

\footnotetext{
13 Many properties of traditional mathematics can be extended to the 'fuzzy' cases. A fuzzification of mathematical concepts is based on a specific generalization of these concepts.
} 
Loret (1903: 20) estimated the length of this area as 118-136 km and concluded that the iteru must have measured ca. $10.5 \mathrm{~km}$. The same idea was applied by L. Borchardt in 1921 for the stretch of Egypt between Syene and the southern tip of the Delta, which is given on the votive cubit rods as 86 iteru. Borchardt (1921: 120) estimated this distance to be $900 \mathrm{~km}$ and obtained the length of the iteru as $900 / 86=10.5 \mathrm{~km}$. With the length of the royal cubit commonly estimated as $0.525 \mathrm{~m},{ }^{14}$ one iteru thus becomes equal to 20,000 cubits - the result which is now widely agreed upon. ${ }^{15}$ The method is, however, not unquestionable: we do not know how this stretch of Egypt was estimated. Along the meandering riverbed of the Nile with all its turnings (as Borchardt assumed) or along the riverbank with shortcuts taken by caravans? Or even as a north-south extension of the land, that is, along a meridian? ${ }^{16}$ In the first case, the iteru was a stage made by a towing team; alternatively, it should be measured in a different way-and the correlation between the two procedures is not obvious. ${ }^{17}$

Next to nothing is known about how the iteru or schoinos might have been adapted for measuring overland distances. Obviously, there existed different possibilities for tackling the problem. For example, a certain stage along the Nile with the length of one iteru could have been fixed as a standard distance and the corresponding overland stage along the riverbank could then have been measured with a metrical gauge, e.g. in cubits. ${ }^{18}$ In this way, schoinos could have been made into a metrological, well defined, measuring unit. The corresponding overland distance could have also been measured by striding, thus making the schoinos an itinerary unit-in this case, the schoinos must have been equal to a certain number of steps. ${ }^{19}$ Another possibility would have been to use the time-equivalent of the iteru to define it as a distance which can be passed over, e.g. in one hour-in this case, the length of the schoinos would have been strongly

\footnotetext{
14 The estimation of the royal cubit as $0.525 \mathrm{~m}$ goes back to R. Lepsius (1866).

15 Whereas L. Borchardt equated the iteru to 20,000 royal cubits, V. Loret assumed that the inscriptions referred to a 'double iteru' and proposed 10,000 cubits for the length of the iteru. Equating the Egyptian schoenus to 12,000 royal cubits was first proposed by Letronne (1851: 101-119,212-246). Such a schoinos would measure $6.3 \mathrm{~km}$.

16 The most conclusive evidence for this possibility is the remarkable precision of the alignment of the sides of the Giza Pyramids (especially Khufu and Khafre) to the north-south direction (that is, along a meridian) known since W. F. Petrie's survey (Petrie 1883: 38-39, 58). This is an especially striking example because in the time of the Old Kingdom the position of the North Pole was not marked by any specific star. E.-F. Jomard (1817), a French cartographer and engineer who had accompanied Bonaparte's campaign of 1798-1801 in Egypt, measured some of the distances and compared them with the ancient textual data. He concluded that the distances are not those of travelled routes; rather they are straight-lines measurements which were gauged exactly. It even led him to propose the existence of geographic maps among the Egyptians.

17 The length of the iteru will also be different for different routes: e.g. the actual distance along the Nile is about $950 \mathrm{~km}$ (which will produce a figure of $11 \mathrm{~km}$ for the iteru) and the length of the caravan route is about $820 \mathrm{~km}$ (corresponding to an iteru equal to $9.56 \mathrm{~km}$ ).

18 In principle, devices like measuring rods or chains can be applied along roads (see note 21 about $\mathrm{H}$. Barth below). Such methods are, however, hardly applicable in the swamps and in the mountain regions.

19 According to Martianus Capella (De nuptiis Philologiae et Mercurii 6.598), Eratosthenes arrived at the distance between Syene and Meroe by using the measurement of the Ptolemaic bematists. Thus, striding was generally in use, but this distance was traditionally transmitted as 5000 stades and we cannot conclude from this textual evidence that the iteru/schoinos used in land surveying could also be defined by a certain number of steps.
} 
dependent upon the precision of the portable time-telling devices ${ }^{20}$ and upon the mode of travelling. It would have been different for pedestrians, mules or camel caravans. ${ }^{21}$ In antiquity, measuring the routes in time units made more sense than labelling them in units of length. The duration of travel and not the length of the route was critical for the vital task of estimation of the amount of water and other supplies required. ${ }^{22}$

The Hellenistic measuring unit stadion differs from the schoinos in the following respect: we hear next to nothing about the 'different' stades in ancient Greek sources. As early as 1882, F. Hultsch in his Griechische und römische Metrologie stressed that:

\begin{abstract}
We generally must refrain from calculating exact distances from indications of stadia in Greek authors. The $\sigma \tau \alpha \dot{\delta} \delta$ เ $v$ can only be assumed to be the conventional expression of 240 steps... Generally speaking, the Greeks actually believed to have only one stadion as unit of measurement; for them, it was the distance of 240 steps; but they ignored with what degree of accuracy and under what circumstances this measure was determined in every single case. ${ }^{23}$
\end{abstract}

Although the stadion was expressed as 600 feet, ${ }^{24}$ long distances were certainly not measured in feet, foot by foot, and then recalculated into stades by equating 600 feet to one stadion. We know that terrestrial measurements in stades were carried out by $\beta \eta \mu \alpha \tau \iota \sigma \tau \eta$ s (bematists) of Alexander the Great, who were trained to maintain the

\footnotetext{
20 The ancient portable Egyptian shadow-clock instrument discussed by L. Borchardt (1911) is still preserved in the Egyptian Museum of Berlin. It is constructed in the following way: along the shadow-receiving ruler some markers are engraved which indicate, according to the instructions, the first, the second, the fourth and the fifth hours after sunrise. The shadow-casting piece of the instrument itself serves as an indicator for the sixth hour (noon). As was shown in Tupikova and Soffel (2013), such an instrument (with a crossbar proposed by L. Borchardt) produces a moderate error only at equinoxes. The portable instruments at that time were not able to tell the time with a precision better than one hour (even much later, Bede the Venerable in De temporibus 703 estimated his punctum $(15 \mathrm{~min})$ as the shortest reliable time-span which could be measured with sundials). The counter-intuitive consequence of the time-dependent definition of schoinos is as follows: because the time span between sunrise and noon (or between sunrise and sunset) could have been defined with no less accuracy than one hour could be, the distances covered over the course of a half day (or a whole day) could have been estimated as accurately as shorter routes.

${ }^{21}$ Rosen (1865: 204) estimated the average speed of a camel as $4.776 \mathrm{~km}$ per hour. More reliable is the estimate of the famous German explorer of North and Central Africa H. Barth. Barth carefully recorded (1849-1855) the time needed for his camel caravan to pass half an English mile (he personally measured the distances with a measuring chain). His best result- $12 \mathrm{~min}$ and $10 \mathrm{~s}-$ leads to an estimate of 2.5 miles per hour (about $4 \mathrm{~km}$ ). The normal speed was estimated by him as barely 2 miles per hour, i.e. ca. $3.2 \mathrm{~km}$ (Barth 2020: 66). A similar estimate was made by the German physician and explorer G. Nachtigal, who measured (1869-1874) this speed in Central Africa, as $3.5 \mathrm{~km}$ per hour for the routes where the camels could eat vegetation available along the way, and as a little bit faster, $4 \mathrm{~km}$ per hour, with favourable surface conditions, and provided that the camels were tied together (Nachtigal 1978: 56).

22 The tradition of marking routes in time units has survived into the modern era: for example, the Saxon post milestones were labelled from AD 1722 in units called 'Wegestunde' (hour's travel) equivalent by definition to $1 / 2$ of a postmile $(=9.062 \mathrm{~km})$. This tradition is preserved in the context of tourism, where walking routes are often estimated in hours.

${ }^{23}$ Hultsch (1882: 55-56): “...wir im allgemein darauf verzichten müssen, aus den Stadienangaben der

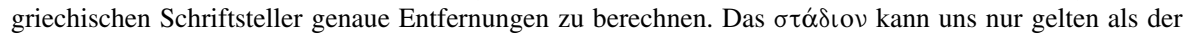
konventionelle Ausdruck für 240 Schritt... Im allgemeinen also glaubten die Griechen wirklich nur ein Stadion als Längenmaß zu haben; es war ihnen schlechthin die Länge von 240 Schritt; allein mit welchem Grade von Genauigkeit und unter welchen Voraussetzungen dieses Maß in jedem einzelnen Falle bestimmt war, ließen sie unbeachtet".

${ }^{24}$ For this ratio see Herodotus 1.178.1, 2.149.3; Vitruvius 3.1.5.
} 
same length of step. ${ }^{25}$ The value of such an itinerary stadion was therefore dependent on the length of step which, in turn, depended on many parameters - the average height of Greek men, the geological profile of the terrain, weather conditions, etc. It is therefore pointless to precisely relate the length of the itinerary stadion to the metrological units used, e.g. in architecture.

Estimates of the heights of adult males in antiquity derived from more than 66 studies of population heights produced a mean result of $168.3 \mathrm{~cm}$ for the height, but the author (Kron 2005: 72) notices that.

We should emphasize at the outset that the height figures derived from ancient cemeteries are likely to underestimate the actual final height of the Greeks or Roman populations, since we are dealing with adult males of all ages, not, as in conscription statistics, with young men. It is very well documented that males tend to reach their final height between 18 and their early twenties, depending upon their level of nutrition, and that their height gradually declines thereafter, particularly in middle and old age, by good $3 \mathrm{~cm}$ or more according to some estimates.

This estimate is backed up by, for example, Roman cemeteries in Germany from the first three centuries $\mathrm{AD}$, where the average height in Hamfelde was found to be $172.1 \mathrm{~cm}$, in Süderbrarup-172.3 cm, in Stettfeld-171.1 cm, in Schwankweiler $-172.7 \mathrm{~cm}$, in Roßdorf- $173 \mathrm{~cm}$, in Groß Gerau- $173.3 \mathrm{~cm}$. As Kron mentions, one should consider that the principal burial grounds were reserved for the warrior class and that their base-born followers were denied proper burial (Kron 2005: 76, n. 35). The average height of males in the particular area of the ancient Metapontion was estimated by Schwartz (2013: 167) to have been between 162 and $165 \mathrm{~cm}$. Recent estimates of ancient Egyptian stature yielding a mean male height of $168 \mathrm{~cm}$ lie close to this range (Zakrsewski 2003).

Many other factors might also influence the average stride length. For example, a pedestrian accompanying a camel caravan had to adjust his speed to that of the camels, thus reducing his own step length. ${ }^{26}$ It is also well known that heavy loads result in a reduction in stride length and an increase in stride frequency. Load mass, load volume and load distribution appear also to be important variables (Knapik and Reynolds 1997).

\footnotetext{
25 'Step length' is the distance between the heel strike of one foot and the heel strike of the opposite foot; 'stride length' is the distance between the heel strike of the same foot. The latter corresponds to the Roman passus.

26 Let us assume, for example, that on a certain terrain the step length of a traveller attains $0.65 \mathrm{~m}$ and the normal speed is $5 \mathrm{~km}$ per hour. Then per hour the traveller makes about 7692 steps. By accompanying a camel caravan with a speed of $4 \mathrm{~km}$ per hour, he had to reduce his step length to $4000 / 7692=0.52 \mathrm{~m}$. The alternative way of adjusting his speed-reduction in the frequency of steps-is extremely energy-consuming and physiologically inconvenient.
} 
Valuable information can be found in reports from modern scholars travelling along the old routes who were interested in measuring distances. Carsten Niebuhr, ${ }^{27}$ a German explorer in the service of Denmark, regularly accompanied camel caravans on foot during the Royal Danish Arabia expedition (1761-1767). He concluded that his speed measured 1580 double steps in half an hour in the heat of the day and 1620 in the cooler times of the day (Niebuhr 1973: 44). What he had measured was the adjusted speed of a traveller (see note 26) and is a very important parameter, because a great part of ancient distances transmitted in stades stemmed from merchants escorting caravans. Provided that the speed of the caravans lay between 3.5 and $4.2 \mathrm{~km}$ per hour (see note 21), we have a rare opportunity to calculate the length of the traveller's step under extreme conditions, in a desert, as between 0.54 and $0.66 \mathrm{~m}$. The German explorer D. G. Schweinfurth has calculated the length of his steps during his African journey (1868-1871) as 0.6-0.7 $\mathrm{m}$ (Schweinfurth 1872: 291ff.). Equating a stadion to 240 steps, we can conclude that its length measured by striding varied between 130 and $158 \mathrm{~m}$ for the first of these researchers, and between 144 and $168 \mathrm{~m}$ for the second.

As it was noticed above, the itinerary measuring units were never precise gauges and, therefore, the ancient agreement equalling 600 feet to 240 steps can only be considered as approximate. Let us estimate the precision of this approximation. Developed for forensic purposes in the mid-1800s, Topinard's formula for estimating a person's height from a footprint gives a foot length: stature proportion of 15\% (Rohren 2009). A cross-cultural archive study by Fessler et al. (2005), involving around 12,000 subjects confirms this old estimate as a mean ratio and estimates the male foot length: stature ratio to be $15.4 \%{ }^{28}$ According to this ratio, the median foot length for a man of $162 \mathrm{~cm}$ height is ca. $24.95 \mathrm{~cm}$ and the corresponding length of the stadion, counted as 600 feet, is ca. $149.7 \mathrm{~m}$; for a man of $172 \mathrm{~cm}$ in height the foot length attained ca. $26.49 \mathrm{~cm}$, which leads to a stadion of ca. $158.9 \mathrm{~m}$. Although we obtained these last estimates by equating the length of a stadion to 600 feet, they are also supported by the estimate of the length of the stadion as 240 steps given above. Rounding these results, we argue that the average length of the itinerary stadion across easy terrain would lie between ca. 150 and $160 \mathrm{~m}$, and we suspect that on more difficult terrains, that figure would be significantly lower, possibly as low as $130 \mathrm{~m}$, because a step length would be shorter. We will formulate this consideration as follows:

Conclusion 1 Long distances estimated by striding, and recalculated into stades by equating 240 steps to one stadion, would assume the average length of a stadion to be around 150-160 m or even less under unfavourable conditions.

The most unequivocal example of the use of the itinerary stadion for short routes in the Ptolemaic or early Roman period in Egypt can be found in S. E. Sidebotham's observation that fifteen pairs of cairns and three single cairns along the Coptos-Myos Hormos road between'Abu Sha'ar and the Nile mark intervals of approximately $1.5-1.6 \mathrm{~km}$ in some places, and about every $3.0-3.2 \mathrm{~km}$ in others (Sidebotham 1986:

\footnotetext{
27 C. Niebuhr was referred to by his son as being of the "average stature" ("Er hatte eine mittlere Statur, war sehr stark und stämmig gebaut", see Niebur 1973: 332) which at that time corresponded approximately to $168 \mathrm{~cm}$ (Baten 1999).

${ }^{28}$ Fessler et al. (2005: 50). See also Henneberg and Henneberg (1998: 519-521); more recently, Schwartz (2013: 173, note 57).
} 
58; Sidebotham 1991: 37, n. 37). The author avoided interpreting these findings because "[n]either of these distances fits with the length of a Roman mile" (Sidebotham 1991: 25). ${ }^{29}$ The numbers do, however, fit with the itinerary stadion, used ten or twenty times. ${ }^{30}$ The comparison of ancient distances with their modern counterparts undertaken repeatedly produced a length of the stadion within the limits we have estimated above. $^{31}$

Although we prefer to strictly differentiate between metrological and itinerary units, we should also mention attempts to estimate the length of Eratosthenes' stadion in a metrological way. Starting with Pliny's remark equating a schoinos to 40 stadia, many scholars calculated Eratosthenes' stadion to have been $157.5 \mathrm{~m} .{ }^{32}$ If such a stadion ever existed as a part of a metrological module, its length should be supported by the smaller elements of the scheme, e.g. by the corresponding foot. Hultsch proposed that this foot measured exactly a half of the royal cubit, that is, $26.25 \mathrm{~cm} .{ }^{33}$ Division of a royal cubit into two parts is well known from the votive cubit rods (Lepsius 1866; Senigalliesi 1961:38-39) and from the inscriptions on the Palermo Stone, one of seven surviving fragments of a stele from the Old Kingdom, which describes measurements of the height of the annual Nile flood. H. Burgsch (1867: 41ff) reads this measure as a 'big foot' and Schäfer (1902) interpreted it as the 'Great Span' of 3.5 palms. The Great Span seems to have been in use before the 5th Dynasty, and later on after the 18th Dynasty (Reinecke 2014: 82).

Textual evidence for such a foot measure was recently found by D. Panchenko (2016). The author noticed that the measurements of the famous tunnel in Samos, reported by Herodotus, gave 8 feet as the height and the width, and 3 feet for the width of the canal inside the tunnel. Archaeological research by Kienast (1995) showed that the height and the width of the tunnel measured $2.1 \mathrm{~m}$, and the width of the canal it contained was $0.8 \mathrm{~m}$. Comparison of these data inevitably leads us to a foot equal to $26.25 \mathrm{~cm}$ (Panchenko calls it a 'Samian' foot $^{34}$ ) and the corresponding length of the stadion measures $600 * 26.25=157.5 \mathrm{~m}$. The author (Panchenko 2016: 186) notices that

\footnotetext{
29 In Sidebotham (2011: 139-140, 147-147) the author notes and discusses the "lack of milestones".

30 Thonemann (2003: 95) gives example of Hellenistic stones which mark distances counted in tens of stades.

31 This comparison can be found by Rennel (1800: 13-34); Gosselin (1813); Gosselin (1819: 21-22, 25-26, 46, 53); Ideler (1826/27); Leake (1839, 11-12); Viedebantt (1915: 214-216); Firsov (1972); Hansman (1981: 3-9); Dutka (1993: 55-56); French (1998: 20); Ferrar (2010), Marx (2014:1-17); Marx (2015: 318).

32 Hultsch (1882: 61) assumes that Eratosthenes' stadion “dasselbe maß als Vierzigstel des Schoinos 300 königliche Ellen..." This view is adopted among others by Letronne (1851: 104-119, 212-246); Müllenhoff (1870: 259-296); Tannery (1893: 109-110); Hultsch (1897: 292); Dreyer (1953: 175); Viedebantt (1915: 232-252), Viedebantt (1920; 94-109); Miller (1919: 6-7); Oxé (1963: 269-270); Aujac (1966: 176-179); Fraser (1972: II, 599, n. 312); Stückelberger (1988: 188); Dutka (1993: 63-4); Meuret (1998, 163-4), Stückelberger (2009: 223-224). Shcheglov (2018: 156) rejects this argument by referring to the famous note by Pliny (Natural History 12.53) that "... a schoinos stretches 40 stades, that is 5 miles" although Hultsch (1882: 60) had already elucidated this misunderstanding. The so-called Egyptian schoenus (Letronne 1851: 101-119) equalling 12,000 royal cubits, leads to a stadion of 300 cubits or $157.5 \mathrm{~m}$.

33 Hultsch (1882: 61): “...der eigene Fuß dieses Stadion betrug gerade die Hälfte der königlichen Elle”.

34 That is, this is exactly the same foot which according to Hultsch (1882: 61) underlies the length of Eratosthenes' stadion.
} 
the 'Samian' foot is nothing but a half of the well-known Samian cubit of $52.5 \mathrm{~cm}^{35}$ and assumes that such a foot was an element of an early body-based metrological system which was later abandoned and replaced by another metrological standard. Some other architectural measures, which point towards the length of the corresponding stadion (Panchenko 2016: 188-189), can, however, be interpreted differently. For example, the racecourse at the sixth century stadium in Corinth which was estimated at between 158 and 165 m (Romano 1993: 43, 49f.) could have been simply measured with steps.

Another attempt to determine the length of the itinerary stadion in a metrological way was based upon the ratio given in the famous table of Heron of Alexandria, according to which one schoinos was equal to four miles. Combining this ratio with the ratio given by Pliny, many scholars arrived at a length of approximately $148 \mathrm{~m}$ for Eratosthenes' stadion. ${ }^{36}$ This figure is also supported by a great deal of textual evidence which allow a comparison of distances transmitted both in miles and stades. ${ }^{37}$ The length of stadion estimated by both methods lies well within the interval which we had set by purely physiological arguments. For simplicity, in the text below we will use in the numerical examples a length of itinerary stadion equal to $157.5 \mathrm{~m}$.

As is well known, the Roman mile has been equated to 1000 passus (2000 steps) or, alternatively, to 5000 Roman feet. With a highly standardized length of Roman foot measured as between 294 and $298 \mathrm{~mm}$, the Roman mile can be estimated as $1478-1482.4 \mathrm{~m}^{38}$ (we will use in the numerical examples the round figure of $1480 \mathrm{~m}$ ). Let us consider now the famous figure mentioned by Strabo- the ratio of 1: 8 between the Roman mile and the stadion-which became a paradigm in modern times. This ratio leads to the estimate of the Greek stadion as ca. $1480 / 8 \mathrm{~m}=185 \mathrm{~m}$. Obviously, a stadion of this length (if it ever existed) could never have been used by bematists. The corresponding stride length would measure $185 / 240=0.77 \mathrm{~m}^{39}$ and the foot $185 / 600$ $=0.308 \mathrm{~m}$ (according to Topinard's formula, it would correspond to a human height of more than $2 \mathrm{~m}$ ). Thus, the distances could not have been measured in such stades by striding. Strangely enough, this 'common-sense' conclusion is mostly ignored by modern scholars ${ }^{40}$ who assume that "this was the 'common stade' used throughout antiquity by default" (Shcheglov 2018: 154). We will formulate this simple consideration as:

\footnotetext{
35 See Hirsch (2013: 50). According to Herodotus (2.168.1), the Samian cubit was equal to the Egyptian cubit.

36 The idea dates back to d'Anville (1741: 15, 48, 57-63) and was supported by Ideler (1826/27: 1-12, 113-118, 126-127); Oxé (1926: 221-223); Diller (1949: 9-10); Prell (1957: 549-563); Fisher (1975: 159-160). Lehmann-Haupt (1929) arrived at a similar result by definition of Pliny's schoinos through the Babylonian cubit of $495 \mathrm{~mm}$.

37 See, e.g. d'Anville (1741: 15, 48, 57-63); Hultsch 1882: 59-60; Oxé 1926: 222; Meuret 1998: 151.

38 Lehmann-Haupt (1929) estimates the Roman mile as being within the range 1471.23-1494 m. See also Hecht (1979: 107-108).

39 This stride length could possibly be achieved along the even Roman roads by soldiers without loads but certainly not along the ancient trading routes.

40 The figure of $185 \mathrm{~m}$ is adopted among others by Bunbury (1959: 209-210); Dicks (1960: 42-46); Cimino (1982: 11-21); Rawlins (1982: 218); Engels (1985: 298-311), Pothecary (1995: 49-67); Berggren and Jones (2000: 14, n.10); Roller (2010: 271-273).
} 
Conclusion 2 Distances estimated by striding and recalculated into stades by equating 240 steps to one stadion could not have been measured in stades equal to $185 \mathrm{~m}$ on difficult terrains.

If not by striding, how else could long distances have been measured in stades of $185 \mathrm{~m}$ ? One can hardly imagine a metrical gauge of such a length - the device must have been smaller and marked with the corresponding units according to the same metrological module. The length of the corresponding foot, measuring $0.308 \mathrm{~m}$ was, however, nowhere attested in the monuments of classical Greek architecture. ${ }^{41}$ As any module had to contain connected elements, in this case one cannot also expect the existence and usage of the corresponding cubit. Last but not least, we do not have any evidence for measuring, for example, the military routes during Alexander the Great's conquests or for measuring the trading routes in the time of Eratosthenes with the help of a technical device. ${ }^{42}$

One can argue that $185 \mathrm{~m}$ was a length of a metrological stadion used only for sports arenas; but how reliable is the evidence from the Hellenistic period which would support this figure? From the dozen sports stadiums preserved from antiquity, only the arena in Athens shows a length which is purportedly close to $185 \mathrm{~m}$ (Fiechter 1929: col.1969; Dinsmoor 1950: 251; Romano 1993: 17, 43, 50 n. 21). This stadium was initially built on the site of the old racetrack by Lycurgus (ca. 330 BC) and completely renovated and decorated by Herodes Atticus in AD 144. The excavation undertaken by E. Ziller in 1869-1870, made it possible to rebuild the stadium for the 1896 Olympics according to the plan of Herodes Atticus (Ziller 1870). Whereas earlier scholars such as Ziller underlined the impossibility of restoring the original length of the racetrack and provided only the total length of the horizontal plane as $204.07 \mathrm{~m}$ (Judeich 1905: 368 ) or the length from the aphesis of the sphendone to the supporting wall as $189.6 \mathrm{~m}$ and estimated the track itself as $177.6 \mathrm{~m}$ (Politis 1896: 46), modern scholars seem to accept the figure of $185 \mathrm{~m}$ without question. One cannot exclude the possibility that the length of the original stadion in Athens could have matched $185 \mathrm{~m}$; but one cannot also exclude the possibility that its length was chosen by Herodes Atticus in his reconstruction as the 'common agreement' ratio of 1: 8 between the Roman mile and the Greek stadion. ${ }^{43}$

How could scholars of the Roman period have developed a conversion coefficient from Roman mile to stadion? Did they compare the transmitted Hellenistic distances

\footnotetext{
41 See Dörpfeld (1882: 277-290) and Dinsmoor (1950: 161, n. 1) about the Doric foot of $326.85 \mathrm{~mm}$ employed in the Parthenon. The foot of $308 \mathrm{~mm}$ is even referred to by the authors as the foot "which no Greek ever employed". The same point is made by Romano (1993: 17, 43, 50 n.1).

42 The odometer first mentioned by Vitruvius and discussed by Heron of Alexandria can be applied along an even road but certainly not on difficult terrain. The method implemented by H. Barth (see note 21) demands the existence and usage of qualitative clocks.

43 Even if the length of a racetrack was thought to comply with a certain metrological value, there were possibly no high metrical standards applied in the construction of stadiums in the years preceding the development of skilled Roman architectural practices. For instance, the stadium in Epidaurus with a track length of $181.3 \mathrm{~m}$, was marked every 100 feet by wooden stakes, but the error amounted to $19 \mathrm{~cm}$ for each stage. See Fiechter (1929: 1969).
} 
with the distances along the Roman roads measured in miles? But Eratosthenes' distances, extensively used, e.g. by Strabo $^{44}$ were certainly not measured along the Roman roads, which did not exist at Eratosthenes' time. If the comparison had been made this way, one would have unavoidably obtained different coefficients (exactly, as modern historians of science do). Were the ancient scholars able to average the majority of the results before the ratio 1: 8 became an accepted figure?

We assume that this coefficient was instead arrived at in a simple arithmetic way and explain it as follows: one Roman mile (RM) was equal to 1000 passus that is 2000 steps and one stadion to 240 steps. If we assume for these ratios-as, according to Hultsch (1882: 53), Polybius already did — the same length of step, we obtain a ratio of the stadion to the Roman mile of

$$
1 \text { stadion }: 1 \mathrm{RM}=\frac{240}{2000}=\frac{1}{8}-0.005,
$$

which gives a 1: 8 ratio as a very good approximation. Thus, in our opinion, one should consider this ratio as a 'common' or 'shared' agreement. According to Strabo, the opposite ratio,

$$
1 \mathrm{RM}: 1 \text { stadion }=\frac{2000}{240} \text { stades }=8 \frac{1}{3},
$$

was used by Polybius (Strabo 7.7.4; Censorinus 13.2).

This does not mean, however, that we can always consider the Roman mile to be a firm metrological unit. It is clear that some distances transmitted in Roman miles were not measured but counted in steps. ${ }^{45}$ Equating the length of a step by Roman and Greeks, we can estimate the length of the corresponding itinerary Roman mile (IRM) as

$$
1 \mathrm{IRM}=\frac{2000}{240} * 157.5 \mathrm{~m} \cong 1313 \mathrm{~m}
$$

In terms of the range of our estimates of the length of the itinerary stadion, between 150 and $160 \mathrm{~m}$, the length of the itinerary Roman mile would lie between 1250 and $1333 \mathrm{~m}$.

\section{Maritime Distances}

Distances measured across the sea in antiquity were normally given either in stades or in terms of a day's sail ${ }^{46}$ which was usually estimated as 500 stades. ${ }^{47}$ Clearly, there is

\footnotetext{
44 As well as by Polybius (Pliny, Natural History 5.40), Agathemerus in Sketch of Geography (3.14; 4.15.,18), etc.

45 From textual evidence we know enough about the Roman surveying technique and devices to conclude that even their methods were unsuitable for measuring very long distances. For example, Lewis (2001: 21-22) suggests that long distances were necessarily counted in steps.

46 The Greek word does not always allow for a distinction between a 'day sail' and a 'day and night' sail'.

47 See Ptolemy's reference to Theophilus and Marinus in Geography 1.9.4. According to the Periplus of Scylax of Caryanda, a man reckoned a 'day and night' run as 1000 stades.
} 
no possibility of measuring a maritime distance by striding or using a measuring rod. A navigator who needs to know the distance covered by his ship at sea can drop a log over the ship's bow and measure the time taken for the log to pass the ship's length. In this case, the speed of the vessel is its length divided by the measured time. Use of such a procedure in antiquity is, however, highly problematic. First, the distance of 500 stades in $12 \mathrm{~h}$ corresponds to ca. 41.7 stades per hour. Thus, velocity can be estimated as $6.6 \mathrm{~km}$ per hour for a stadion length of $157.5 \mathrm{~m}$ (and as $7.7 \mathrm{~km}$ for a stadion of $185 \mathrm{~m}$ ). For a vessel of $30 \mathrm{~m}$ length, a log needs 16 (or correspondingly, 14) seconds to pass the whole ship. Such small units of time cannot be measured with ancient sundials or water clocks. Secondly, the length of the ship would hardly be measured in stades but rather in metrological units such as the cubit or foot. One foot corresponding to the 'standard' stadion of $185 \mathrm{~m}$ would be $308 \mathrm{~mm}$. Because it was not applied in classical architecture (see note 41), it could not have been used in shipbuilding and the logging procedure would not have provided distances at sea expressed in the 'standard' stadion of $185 \mathrm{~m}$.

We can assume that early coasting practice ${ }^{48}$ helped pilots and masters of ships to develop a sense of the length of a sailing route: "during coastwise sailing, where the land distances between point and point were known, they must almost unconsciously arrived at a scale" (Taylor 1971: 52). And, provided that land distances were measured by striding, that is, in the itinerary stades, the lengths of sea routes were also expressed in these units. 49

It seems that coasting was no longer a current practice by the time of Eratosthenes. As transmitted by Strabo (1.3.2), Eratosthenes claimed that.

The Ancients whether out on piratical excursions, or for the purposes of commerce, never ventured into the high seas, but crept along the coast.

P. Arnaud (2011: 60) emphasized that: "This does not mean, however, that coasting was a forgotten practice, but that by the time of Eratosthenes sailors did not have to follow the coasts and knew other forms of sailing that fitted better with the supposed goals of maritime trade". That the Greek sailors frequently sailed in open seas cannot be denied. Experience gained by coasting, where the landmarks were visible at a distance, ${ }^{50}$ helped navigators and sailors to learn to calculate the progress made by their ships across the sea:

For every master and pilot prided himself on knowing exactly how much way his ship was making. He knew the ship, he considered the wind, he watched

\footnotetext{
48 Coasting is not the same as cabotage (sailing from cape to cape), or tramping (sailing from port to port). For trading practices and patterns see Arnaud (2011: 59-61).

49 It is interesting to reconsider from this point of view the sailing routes in the Mediterranean first mentioned in a book entitled Lo Compasso da Navigare, which most scholars date to AD 1250. The unit of distance employed in this book, the millara, has sometimes been described as the 'little sea mile', with a length approximately five-sixths that of the Roman mile (Taylor, 1971: 105-106). This figure-1235 m-is close to our estimation of the itinerary Roman mile. Could this measuring unit have originated from the comparison of sailing routes with land distances measured in Roman miles by striding?

50 "My home is under the clear skies of Ithaca", said Odysseus (Book IX 1.19-21), "our landmark is the wooded peak of windswept Neriton".
} 
the sails, he watched the water. In fact, it was a matter which just could not be explained to the landsman. A good sailor knew his ship, and that was all. ${ }^{51}$

A day's sail was a notional distance which a ship could achieve during a 12-h run with a fresh following wind (thus, a recognizable pattern of prevailing or most frequent winds played an important role). ${ }^{52}$ The definition implies that maritime distances were estimated under optimal travelling conditions preferably along the shortest route between ports and corresponded to the shortest travel time. A day's run of 500 stades seems to be simply a round figure, but the estimate was accurate: according to Datoo (1971: 65), Arab dhows sailing from their home ports took 30 to 40 days to reach Mombasa or Unquja, travelling around $75 \mathrm{~km}$ per day. A day's run of 500 itinerary stades comes very close to this figure $(500 * 0.1575 \mathrm{~km}=78.75 \mathrm{~km})$. It is worth mentioning that for safety's sake it was preferable to take the higher reckoning rather than the lower to avoid shipwreck at night, the sailor's greatest dread. ${ }^{53}$

Before we consider some pieces of evidence which can allow us to estimate the length of a stadion and precision in measuring ancient land and sea routes, we should discuss some practical problems of such calculations.

\section{Pitfalls of Recalculation}

Is it possible to unambiguously estimate the length of the stadion used in antiquity? Generally speaking, two cases should be considered separately: first, distances initially estimated in stades and secondly, distances initially measured in Roman miles and later recalculated into stades. Such recalculations could be performed, e.g. for the sake of comparison or structural uniformity with other distances (as Strabo often did). A significant proportion of Ptolemy's data is likely to have been based on distances measured in Roman miles and recalculated by him into stades to convert the distances into angular measures, by equating 500 stades to $1^{\circ}$. Often, we cannot be certain which case we are dealing with (neither do we know whether the distances were estimated by striding or measured using some technical device). Whereas in the first case we can hope to estimate the length of the stadion directly, the second case is much less straightforward. Nevertheless, it is the second case which can provide us with additional valuable information.

Let us consider a numerical example. We assume that a distance between two locations A and B (let us call it 'D') equal to $148 \mathrm{~km}$ was measured by Roman surveyors with high precision in Roman miles $(1 \mathrm{RM}=1480 \mathrm{~m})$ and thus reported as:

$$
\mathrm{D}^{\mathrm{RM}}=\frac{\mathrm{D}}{1 \mathrm{RM}}=\frac{148000}{1480}=100 \mathrm{RM}
$$

\footnotetext{
51 Taylor (1971: 121).

52 A following wind was of primary importance in antiquity, when a loose billowing square sail was in use. For example, Pliny describes a French wind Circius as one that would carry a ship from Narbonne across the Ligurian sea to Ostia. He also says that from Carphatus it is 50 miles with the wind Africus to Rhodes. 53 This advice is given, for example, in the Spanish translation of the oldest surviving Portuguese navigation manual, the Regimento do Astrolabio e do Quadrante, printed in Lisbon around 1509 (Taylor 1971: 167).
} 
Let us assume now that an ancient scholar wanted to refer to this distance in stades in his text. Provided that he used the ratio of 1: 8 for such a recalculation, this distance would have been calculated by him in stades as:

$$
\mathrm{D}^{\mathrm{st}}=\mathrm{D}^{\mathrm{RM}} * 8=100 * 8=800 \text { stades. }
$$

Now, suppose we are lucky enough to have found his scholia with information about these two locations, A and B, with the distance between them given as 800 stades. If both locations are identified, and their actual latitudes and longitudes are known-let us call them $\varphi_{\mathrm{A}}, \lambda_{\mathrm{A}}$ and $\varphi_{\mathrm{B}}, \lambda_{\mathrm{B}}$, respectively-we can calculate the actual distance $\mathrm{D}$ between them with the help of the spherical law of $\operatorname{cosines}^{54}$ :

$$
\cos D=\cos \left(90^{\circ}-\varphi_{A}\right) \cos \left(90^{\circ}-\varphi_{B}\right)+\sin \left(90^{\circ}-\varphi_{A}\right) \sin \left(90^{\circ}-\varphi_{B}\right) \cos \left(\lambda_{A}-\lambda_{B}\right) .
$$

$\mathrm{D}$ will be found to be $148 \mathrm{~km}$ (we have assumed that measurements were executed accurately) and we will estimate the 'length of a stadion' as:

$$
\text { Length of the stadion }=\frac{D}{D^{s t}}=\frac{148000}{800}=185 \mathrm{~m} \text {. }
$$

Does that mean that this distance was measured in stades with the length of the stadion equal to $185 \mathrm{~m}$ ? Not at all. If the ancient scholar had recalculated the distance measured in Roman miles into stades according, for example, to the ratio of 1: 10, he would have given the distance as:

$$
D^{\text {st }}=D^{\mathrm{RM}} * 10=100 * 10=1000 \text { stades, }
$$

and we would have estimated the 'length of a stadion' as:

$$
\text { Length of the stadion }=\frac{D}{D^{s t}}=\frac{148000}{1000}=148 \mathrm{~m} .
$$

Likewise, this figure does not mean that the length of a stadion was equal to $148 \mathrm{~m}$. It only means that the figure which we obtain for the length of the stadion in this way reflects the ratio adopted by an ancient scholar. If we obtain a result close to $185 \mathrm{~m}$, this means simply that the author used the ratio of 1: 8 ; if we obtain a result close to 148 , this means that the ratio in use was $1: 10$. The result can, of course, also be obfuscated by the unknown precision of the measurement.

The situation becomes more complicated for distances measured by striding, namely in units which we have called 'itinerary' Roman miles (IRM). Let us assume

\footnotetext{
54 The use of the more precise Vincenty inverse formula to calculate an ellipsoidal distance makes little sense in this case.
} 
that on dry land the length of the IRM was $1313 \mathrm{~m}$. Then, the distance of $148 \mathrm{~km}$-let us call it $D^{\mathrm{IRM}}$ _has been estimated as ${ }^{55}$ :

$$
D^{\mathrm{IRM}}=\frac{D}{1 \mathrm{IRM}}=\frac{148000}{1313} \cong 113 \mathrm{IRM}
$$

To recalculate the distance into stades, an ancient scholar could have used the 'common-agreement' ratio of $1: 8$ or Polybius' ratio of $1: 8 \frac{1}{3}$; in these cases, by comparing the reported distance with its actual counterpart we obtain a length of the stadion equal to ca. $164 \mathrm{~m}$ and $157 \mathrm{~m}$, respectively. This common-sense consideration seems to us so important that we would like to formulate it in the following conclusion:

Conclusion 3 For ancient distances estimated in certain measuring units but transmitted in the ancient sources as recalculated in stades, the length of the stadion deduced from their comparison with the actual distances depends upon the ratio used in these recalculations.

The simple numerical examples given above show that for the distances measured in Roman miles and recalculated into stades an unambiguous solution for the length of the stadion is not possible - for such calculations we need distances originally estimated in stades. Such recalculations have, however, their own problems.

Let us consider an overland route from A to B transmitted in an ancient source as D. Without knowing the exact course of the ancient route, the only way it is possible to estimate the distance between two locations is to calculate it using their geographical coordinates. Such a distance is - by calculation - an arc of a big circle connecting two locations, and it represents the shortest possible route between A and B. Obviously, the length of the ancient route D was always bigger than the shortest distance, and by comparison of the ancient route with the actual distance we will always obtain a length of the stadion smaller than the value originally used (provided that the route was measured or estimated accurately enough). We can therefore infer that the most accurate comparison of ancient distances with their modern counterparts can best be accomplished based on routes measured along the arcs of the big circles. The course of a road can change with time but the length of the shortest route remains effectively constant. The Greeks gave such overland or oversea distances using the idiom 'as the crow flies'. Of course, any meridian is also a big circle, and distances measured along meridians are of primary importance for such estimates. ${ }^{56}$ Locations lying on the same meridian were referred to in antiquity as 'situated opposite'. But here we encounter the next problem: not all of them were in fact situated on the same meridian.

\footnotetext{
55 All the computations were performed with 15 digits. Results given here are rounded to the nearest whole number.

56 Distances between locations situated on the same parallel are not the shortest distances; this mathematical fact was possibly not commonly known in antiquity. Nevertheless, the distances given 'along a parallel' were corrected for the twists and turns of the routes, thus being approximately close to 'straight line' distances.
} 


\section{Pitfalls of Statistics}

One of the most prominent ancient distances was related to Eratosthenes' measurement of the circumference of the Earth - this is the distance between Alexandria and Syene. ${ }^{57}$ Both locations were surmised to lie on the same meridian and the latter was assumed to be situated below the summer tropic. ${ }^{58}$ The distance between the two locations was estimated as 5000 stades. ${ }^{59}$ A question in dispute ever since is whether this distance was measured along a travel route or estimated as the shortest distance between these locations. In the method reported by Cleomedes, however, it must have been surmised as measured along the meridian ${ }^{60}$ and with the actual distance between these locations of ca. $845 \mathrm{~km}$, we can calculate the corresponding length of the stadion as $845,000 / 5000 \cong 169 \mathrm{~m}$. For the length of the itinerary stadion between 150 and $160 \mathrm{~m}$, the precision of the estimate of this distance is, therefore, ca. $11 \%$ and 5\%, respectively. Another 5000 stades south from Syene, another famous location-Meroe-lay (supposedly) on the same meridian. ${ }^{61}$ Calculating the modern distance between Syene and Meroe and dividing it by 5000 stades, we arrive at a length of the stadion close to $160 \mathrm{~m}$. The distance of the Canopic mouth of the Nile from

57 The description of the method was transmitted by Cleomedes 1.7.49-110 (Bowen and Todd 2004: 81-84). According to him, Eratosthenes calculated the circumference of the Earth as 250,000 stades although most ancient authors generally give Eratosthenes's result as 252,000 stades (Vitruvius 1.6.9; Strabo 2.5.7, 2.5.34; Pliny, Natural History 2.247f.; Theo of Smyrna, On Mathematics Useful for the Understanding of Plato (Hiller 1995: 124.10-12; 127.9); Galenus, Introduction to Logic 12.2; Censorinus, The Birthday Book 13.2; Martianus Capella, Marriage of Philology and Mercury 6.96; Geminus, Introduction to the Phenomena 16.6-9). The common consensus is that this value might have been introduced as a convenient approximation which makes it easy to divide the result into 60 parts (and later makes one equator degree exactly equal to 700 stades). Carman and Evans (2015) proposed an interesting hypothesis as to how Eratosthenes could have arrived at the figure of 252,000 stades due to the final size of the Sun. A recent publication (Tupikova 2018) shows how Eratosthenes could have obtained exactly this figure with the aid of available geographical information and simple geometrical modelling.

58 In fact, Alexandria (ca. $31^{\circ} 12^{\prime} 19^{\prime \prime} \mathrm{N}, 29^{\circ} 55^{\prime} \mathrm{E}$ ) and Syene (ca. $24^{\circ} 05^{\prime} \mathrm{N}, 32^{\circ} 54^{\prime} 20^{\prime} \mathrm{E}$ ) do not lie on the same meridian - the difference in longitude is about $3^{\circ}$, and Syene was not situated below the summer tropic in Eratosthenes' time (the mean ecliptic in Eratosthenes' time varied between $23^{\circ} 43^{\prime} 45^{\prime \prime}$ and $23^{\circ} 43^{\prime} 08^{\prime \prime}$ ). Nevertheless - in the method ascribed to Eratosthenes by Cleomedes - the errors of Eratosthenes' procedure have partially cancelled each other out (Tupikova 2018: 225).

59 This is confirmed, e.g. by Strabo 2.5.7; Pliny, Natural History 2.183, 184.

60 According to Cleomedes (Bowen and Todd 2004: 81), "Eratosthenes says, and it is the case, that Syene is located below the summer tropical circle. So when the Sun, as it enters Cancer and produces the summer solstice, is precisely at this meridian, the pointers on the sundials are necessarily shadowless, since the Sun is located vertically above them... But in Alexandria at the same hour pointers on sundials do cast a shadow, since this city is located further north than Syene. Now since the two cities are located below a meridian (a great circle), if we draw an arc from the tip of the pointer's shadow on the sundial at Alexandria round to the base of the pointer, this arc will be a section of the great circle in the sundial's bowl, since the sundial's bowl is located below a great circle".

61 Strabo 2.5.7. Strabo also informs us (2.10.20) that Eratosthenes possessed the information about the latitude of Meroë: "Regarding the latitude of Meroë, Philon, who wrote about his voyage to Aithiopia, records that the sun is at the zenith forty-five days before the summer solstice, and also discusses the relationship of the gnomon shadows of both the solstices and equinoxes. Eratosthenes is closely in agreement with Philon" (Roller 2010: 66). 
Syene, estimated by Eratosthenes as 5300 stades (Strabo 17.1.2 and 17.1.4), results in a length of the stadion also equal to ca. $160 \mathrm{~m}^{.62}$

We suggest that an examination of long sea routes can make a valuable contribution to the quantitative analysis of the length of a stadion. Certainly, these routes should be evaluated with caution: ships never sail along the shortest route but choose routes according to changing winds and currents. When multiple outward and return trips are taken into account, the variables of wind and tide partly balance out; we can also assume that the courses of the sea routes described in terms of 'as the crow flies' must have been somehow corrected for the twists and turns. ${ }^{63}$ For example, the distance across the sea between two landmarks, Rhodes and the mouth of the Tanais River, was transmitted 'as the crow flies' and estimated to be 10 day and night runs (i.e. 10,000 stades) by Diodorus (3.4.7). With the length of an itinerary stadion between 150 and $160 \mathrm{~m}$, one arrives at a distance in the range of $1500-1600 \mathrm{~km}$, in comparison with the true figure of ca. $1550 \mathrm{~km}$.

Very promising in terms of estimating the length of the stadion are the cabotage and the tramping routes. Looking in particular at cabotage (where one navigated from one observable cape to another), the stages can be reliably approximated using the corresponding arcs of big circles. Many such distances can be extracted from the handbook on trade in the Indian Ocean-Periplus Maris Erythraei-written by an unknown captain or merchant between AD 40 and 70 (Casson, 1989). The 'long distance' of 22,600 stades from Berenike to the Isles of Sarapis (Foul Bay to Masirah Island) was compared by L. Casson (1989: 281) with a true distance of approximately 1850 nautical miles $(1$ nautical mile $=1852 \mathrm{~m})$. Assuming the length of the stadion to be $185 \mathrm{~m}$, Casson classified this distance as overestimated by ca. $20 \%$. We can, however, instead calculate for this distance the corresponding 'length of the stadion': it works out as $1852 * 1850 / 22600=151.6 \mathrm{~m},{ }^{64}$ and then the route seems to be estimated accurately.

So far, we have considered a number of individual though well-documented cases; but are these sufficient to draw a conclusion about the length of the stadion used in antiquity? Or should we argue that "we can never be sure that the length of the stade determined from these rare reconstructions will represent a general pattern, rather than just a local or random deviation from the norm" (Shcheglov 2018: 161)? Should we not try to make the sample as large as possible to ensure greater reliability in the result?

To begin with, to make the statistical investigation reasonable, we should choose distances initially measured in stades and not recalculated into stades according to a certain rule (see Conclusion 3 ). These distances should also have been measured along

\footnotetext{
62 Priskin (2004) suggests that Eratosthenes (as well as Strabo) borrowed Egyptian measurements originally made in iter $u$ which were later recalculated into stades according to the rule 1 iteru $=50$ stades (in fact, distances in Strabo's descriptions of the Nile are all multiples of one hundred and thus, of course, are divisible by 50). In this case, however, the question arises: why do the distances measured in such iteru match the actual (shortest) distances in Egypt?

63 A passage of Strabo 2.5 .7 (Roller 2014: 132) gives an impression of disputable matters:”...everyone agrees that the sea route from Alexandria to Rhodes is in a line with the course of the Nile, as well as the sailing route from there along Karia and Ionia to the Troad, Byzantion, and the Borysthenes. Taking then, the known distances that have been sailed, they consider how far the territories in a straight line beyond the Borystenes are inhabited and what the boundary is of the part of the inhabited world towards the north".

${ }^{64}$ For a very inspiring insight into navigational techniques used in the ancient Red Sea see Seland (2020).
} 
the shortest possible routes connecting every pair of locations. To this class belong not only the distances measured along the meridians but also the distances prepared for cartographical purposes which have been corrected for twists and turns in the routes. ${ }^{65}$ Obviously, the available data sets are inconsistent and heterogeneous and the challenge is to differentiate and select from among all transmitted ancient distances those satisfying the conditions mentioned above. Thus, we argue that the statistical estimates of the length of a stadion should be viewed with caution.

As an example, we will discuss here the recent paper of D. A. Shcheglov (2018) entitled "The so-called 'Itinerary Stade' and the Accuracy of Eratosthenes' Measurement of the Earth" in which the author claims to conclusively reject the existence of the itinerary stadion with the aid of statistical analysis.

After detailed presentation of written evidence for the 'short stade', the author proceeds in the following way. First, the ancient distances transmitted by Eratosthenes and Strabo are divided into four main groups: overland distances, distances across the open sea, maritime distances along the coast and those along rivers (the last group was excluded from the analysis). ${ }^{66}$ Secondly, "the corresponding distances on the modern map (in Google Maps) have been measured simply by a straight line for the overland and oversea routes, or by the shortest way with minimum bends for those along the coast". 67 Thirdly, for every ancient route the length of the stadion was calculated through the division of the length of the modern distance in meters by the length of the ancient route in stades. Finally, the 'weighted' mean length of the stadion was calculated for each group as the total sum of the modern distances in meters divided by the total sum of the distances in stades. We summarize Shcheglov's final results for three important groups of distances in Table $1 .{ }^{68}$

As the author concludes, "this result might have been regarded as a brilliant confirmation of the short stade hypothesis" (Shcheglov 2018: 164), but declines to accept it due to the following consideration. He repeats the same procedure for the data transmitted by Pliny, in the Antonine Itinerary (ca. AD 300), and in the Stadiasmus of Patara (ca. AD 45-46) and obtains a 'weighted' mean length of the Roman mile of between $1123 \mathrm{~m}$ (for the overland distances 'without outliers' and over 250 miles)

\footnotetext{
65 One should notice that only the short- and intermediate length routes along a parallel can be compared with the arcs of the great circles connecting the locations; the longer routes decline noticeably from the shortest distances and should be calculated differently.

66 From the numerical analysis were also excluded-without any mathematical justification-distances resulting in a length of the stadion under $100 \mathrm{~m}$ and over $200 \mathrm{~m}$ for Eratosthenes' and Strabo's distances, and those leading to a length of the Roman mile under $750 \mathrm{~m}$ and over $1750 \mathrm{~m}$ (Shcheglov 2018: 164 and 167, respectively). The author also excludes from his analysis of Strabo's distances those under 1000 stades "because only one of Eratosthenes' distances falls below this limit" and from the analysis of Roman distances, those "under 1000 stades = 250 miles" (Shcheglov 2018: 164). We might consider this puzzling statement to be a typographical error if it was not repeated in Table 3. Because for the length of the stadion ( $185 \mathrm{~m}$ ) favoured by Shcheglov, 1000 stades correspond to $185 \mathrm{~km}$, but 250 miles are approximately equal to $370 \mathrm{~km}$, such a choice leads to the favouring of longer Roman distances (measured preferably in itinerary measures). In the interest of consistency, the author would have been better advised to set the limit at 1000: $8=125$ miles.

67 Shcheglov 2018: 161. We assume that 'straight-line' distances have been measured using Google Maps' tool 'lineal'.

68 We give here the results for all distances. The author also considers separately 'distances without outliers' (terminology will be discussed later).
} 
Table 1 'Weighted' mean length of the stadion derived from Eratosthenes' and Strabo's distances (after D. A. Shcheglov 2018)

\begin{tabular}{|c|c|c|c|c|}
\hline \multicolumn{3}{|l|}{ Eratosthenes } & \multicolumn{2}{|l|}{ Strabo } \\
\hline $\begin{array}{l}\text { Groups of } \\
\text { distances }\end{array}$ & $\begin{array}{l}\text { Number of } \\
\text { distances }\end{array}$ & $\begin{array}{l}\text { Weighted mean } \\
\text { length of the stadion } \\
\text { (in meters) }\end{array}$ & $\begin{array}{l}\text { Number of } \\
\text { distances }\end{array}$ & $\begin{array}{l}\text { Weighted mean } \\
\text { length of the } \\
\text { stadion (in } \\
\text { meters) }\end{array}$ \\
\hline $\begin{array}{l}\text { Overland in a } \\
\text { straight line }\end{array}$ & 28 & 143.64 & 154 & 160.6 \\
\hline Along the coast & 14 & 161.09 & 92 & 148.2 \\
\hline $\begin{array}{l}\text { Oversea in a } \\
\text { straight line }\end{array}$ & 2 & 153.48 & 49 & 150.7 \\
\hline
\end{tabular}

and $1196 \mathrm{~m}$ (for all distances across open sea). The author considers the result to be a consequence of an overestimation of these distances by $25-30 \%$ on average and concludes that Eratosthenes' and Strabo's distances must have also been 'overestimated' by the same amount, which would be the case "if they were expressed in the common stades of $185 \mathrm{~m}$ " (Shcheglov 2018: 166). The terminology is potentially misleading: 'overestimation' might mean simply that the ancient route was longer than the length of the shortest distance between two locations on the modern map.

Before discussing the details of this statistical analysis, let us advance some objections of a mathematical character. First, statistical methods can be applied only to sufficiently large data sets. How big a set should be, depends upon the quality of the data, their nature and origin (dependent/independent sources, clustering, the possibility of systematic errors). Secondly, popular statistical methods tend to rely heavily on the assumption that data errors are normally distributed or converge on a normal distribution. Only in this case-due to the Central Limit Theorem-will a sample mean tend to the population mean (of the whole measured distances which we do not know). The measuring errors should be independent random variables generated in such a way that any value does not depend on the other measurements, and should result from independent random effects, without any dominants. ${ }^{69}$ However, ancient distances were estimated in a variety of different ways (e.g. by striding for long distances, by measuring by some technical means for shorter distances, by recalculating distances given in foreign units, etc.) and in general we should expect at best a set of normal distributions with different systematic errors and with different mean values-and the calculation of a single mean value could be highly misleading. Thirdly, possibly the principal mistake of the study was the choice of 'weighted' mean lengths of the stadion and the Roman mile as the basis for the analysis. Using this method, individual distances cannot be considered as independent equally weighted items, and long distances will dominate the results of the calculations. For example, let us consider two ancient distances, 1000 stades and 5000 stades long, and assume that these distances

\footnotetext{
69 When there are many outliers in the data (transcribing errors over the course of time, or errors attributable to the use of different measurement units and erroneous recalculations), the classical estimators show poor performance. Outliers can also often interact in such a way that they mask each other.
} 
correspond on modern maps to distances of $185 \mathrm{~km}$ and $785 \mathrm{~km}$, respectively. Then, for the first route the length of the stadion can be calculated as $185,000 / 1000=185 \mathrm{~m}$ and for the second as $785,000 / 5000=157 \mathrm{~m}$. The simple mean length of the stadion attains $(185 \mathrm{~m}+157 \mathrm{~m}) / 2=172 \mathrm{~m}$ and is based upon the assumption that both data should be equally weighted units. The 'weighted' mean length of the stadion would be smaller $(185,000+785,000) /(1000+5000)=161.67 \mathrm{~m}$ because the longer distance (measured with a shorter stadion) is overweighted in the calculation. ${ }^{70}$ The use of this type of 'weighted' mean is, in fact, equivalent to the assumption that long routes were measured more accurately than the short routes.

But our general objection concerns the general line of reasoning of this publication. Distances attributed to Eratosthenes by later authors are mostly data taken from his cartographical studies-i.e. distances along meridians or parallels already corrected by the scholar for their digression from the straight routes. ${ }^{71}$ Such a correction could have been made in a number of ways: by an educated guess, by adjusting to other routes $^{72}$ or with the aid of available astronomical information. ${ }^{73}$ A significant part of Strabo's distances (since he was thinking along similar lines to Eratosthenes and often used Eratosthenes' data without mentioning his source) probably goes back to a cartographical tradition, but much of his data also stemmed from the Roman sources. The latter have been partly recalculated into stades according to some fixed rules, and generally not corrected for the purposes of cartography. We argue therefore that Strabo's distances should have a mixed character. As to Pliny's data, the distances transmitted by the author were generally not corrected for cartographical purposes. Some of them could have originated from Greek cartographers but the majority of distances digressed significantly from 'straight lines' routes. In our opinion, the strikingly different origin of systematic errors for these classes of data does not allow any direct comparison of statistical results.

Our aim was not to check or correct the identifications and geographical coordinates given by Shcheglov ${ }^{74}$ but to evaluate the validity of his conclusions. Thus, we have taken for granted the author's data for the length of the stadion or the Roman mile given

\footnotetext{
70 If the routes had the same length, the 'weighted mean' would be equal to the simple mean. Of course, with only two distances involved in our example, both figures are misleading.

71 Strabo consistently objects (e.g. 2.1.33) when in his own opinion Eratosthenes' distances digress from parallels or meridians.

72 By adjusting on a map two incoming routes estimated with the same systematic error, this error can be reduced. The more routes involved in the cartographical procedure, the higher is the general accuracy of the result.

73 For example, according to Strabo 4.5.24, Eratosthenes was able to estimate the distance between Alexandria and Rhodes as 3750 stades by using gnomons. This presupposes positioning both locations on the same meridian - the mutual distance is then proportional to the central angle spanning the arc of the meridian between Alexandria and Rhodes. In this case-because Eratosthenes' measurement of the Earth as 252,000 stades turned out to be very precise in terms of the length of the itinerary stadion - the distances calculated with the help of the known gnomon-ratios would have tended to be accurate in these stades. For methods of recalculating the gnomon-ratios in the arcs of the meridians see Tupikova (2018: 248-249).

74 The author supplied his text with Googledrive links to the EXCEL tables containing details of the locations, their actual geographical coordinates (taken from the Digital Atlas of the Roman Empire, unfortunately, unavailable online at the time of writing this paper), the distances between them as transmitted in ancient sources, the actual distances estimated with the aid of Google Maps, the lengths of the stadion or of the Roman mile calculated for every pair of the locations by dividing the length of true distance between
} 

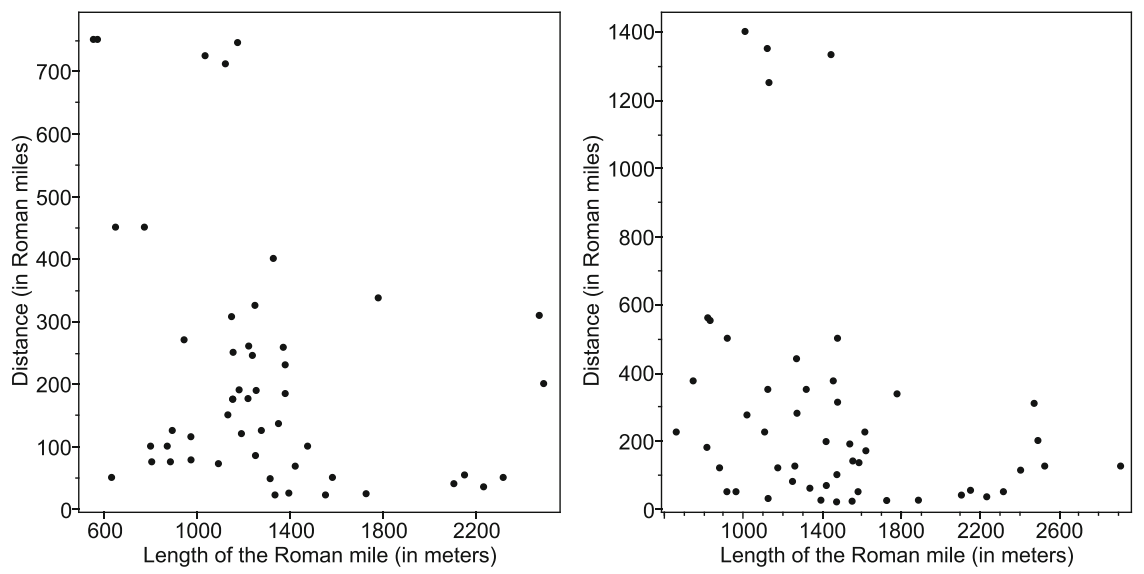

Fig. 1 Length of the Roman mile vs. Pliny's distances. Left: overland distances. Right: oversea distances

for every pair of locations, although some of his data do not correspond to the given coordinates. ${ }^{75}$ We assume that the errors can be partly attributed to the manual use of Google Maps instead of calculation of the distances from the coordinates and partly to the typographical errors in the coordinates in the EXCEL tables. In our opinion, the whole endeavour should be put on a more solid historical and mathematical basis—but this lies far beyond the scope of our text. Thus, the following analysis should be considered purely as preliminary and is given here primarily to illustrate the problems of the statistical methods.

In the following, we will consider the entire set of lengths of the stadion and the Roman mile calculated by Shcheglov to reveal the information obfuscated by the single 'weighted mean' value. To be consistent with the author's method, we divide the data into two groups corresponding to distances under (or equal to) 1000 stades or 125 miles, and those over this limit. Let us look first at the distances transmitted by Pliny which were chosen as the background for the comparison. Figure 1 shows the length of the Roman mile vs. Pliny's corresponding distance. One can immediately understand the source of the 'overestimation of distances' proposed by Shcheglov. Some data which indicate lengths of the Roman mile ranging between 1100 and $1200 \mathrm{~m}$ correspond to the greatest distances and enter the calculation of the 'weighted' mean with the biggest weights, thus reducing the resulting mean figure. ${ }^{76}$ It is interesting

Footnote 74 continued

them by the ancient distance and a single 'weighted mean' value for the selected sets of data (overland, along the coast, across an open sea).

75 For example, for 153 overland distances taken from Strabo, the length of the stadion which we have calculated with the help of the geographical coordinates given in the EXCEL tables differs in 16 cases from the lengths of the stadion given by Shcheglov by more than $10 \mathrm{~m}$; from 48 distances across open sea, 7 lengths of the stadion have an error greater than $10 \mathrm{~m}$.

76 In general, a figure smaller than $1480 \mathrm{~m}$ points towards an 'overestimation' of a distance and a figure bigger than $1480 \mathrm{~m}$ towards an 'underestimation'. Whereas the 'overestimation' is easy to understand as a consequence of measuring routes with all their twists and turns or as a usage of the itinerary units, 'underestimation' can go back either to the errors in the manuscripts or to erroneous recalculation of the foreign measuring units. For example, let us assume that a distance of $160 \mathrm{~km}$ has been estimated as 1000 

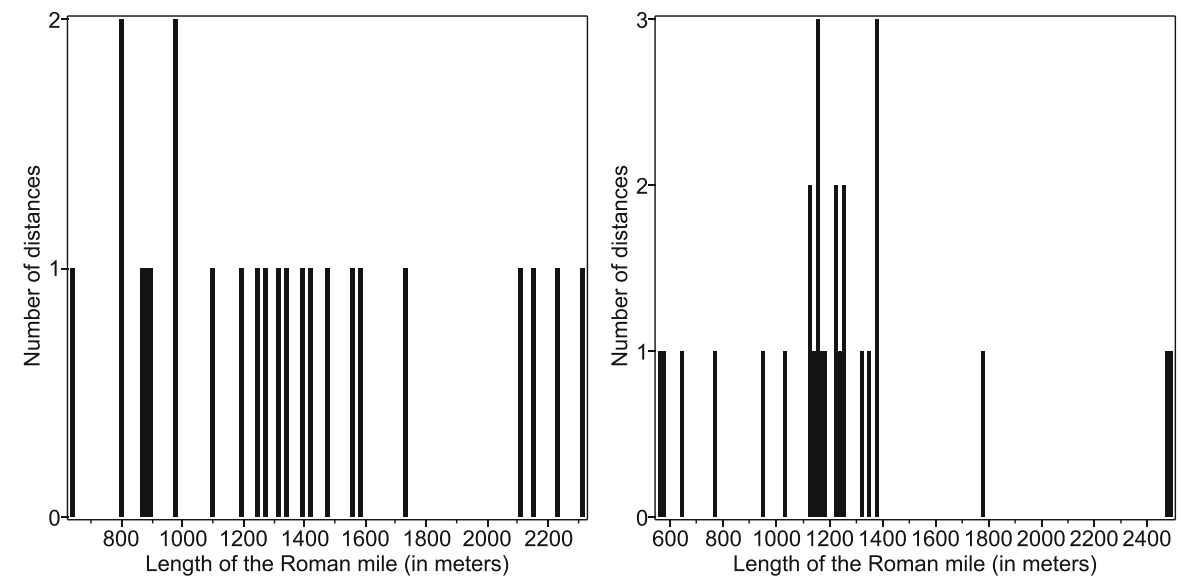

Fig. 2 Length of the Roman mile from Pliny's overland distances. Left: distances under (or equal to) 125 Miles. Right: distances over 125 Miles

that the lengths of the Roman mile calculated on the basis of shorter distances (under ca. 150-250 miles) show significantly more variability than those based on longer distances. This observation contradicts Shcheglov's main argument, and yet it is ignored in his analysis.

Figure 2 provides a more detailed examination of Pliny's overland distances. Distances under 125 miles (left) show a cluster around $900 \mathrm{~m}$ for the length of the Roman mile, ${ }^{77}$ some outliers at the right-hand side of the histogram and a second cluster with the lengths of the Roman mile at $1000 \mathrm{~m}$ to $1800 \mathrm{~m}$. The latter cluster shows a normal distribution with a mean value of the Roman mile equal to $1385.8 \mathrm{~m}$ (which is very close to the actual figure) and a standard deviation of $141.5 \mathrm{~m}$. The distances over 125 miles (right) show two obvious clusters - at about $1200 \mathrm{~m}^{78}$ and about $1380 \mathrm{~m}$. These figures strongly contradict the 'weighted' mean estimated by Shcheglov as $1147 \mathrm{~m}$ for Pliny's overland data.

Figure 3 shows Pliny's distances across the sea. The shorter distances (Fig. 3, left) lead to a cluster of about $900 \mathrm{~m},{ }^{79}$ and to a group between 1150 and $1450 \mathrm{~m}$ which may have originated from the distances corrected for their twists and turns and to some obvious outliers on the right-hand side of the graph. The spectrum of results for distances over 125 miles (Fig. 3, right) seems to be more dispersive but clearly shows a

Footnote 76 continued

stades and later recalculated into the Roman miles according to the 1:10 rule. It was then transmitted as 100 Roman miles. Comparing the true distance of $160 \mathrm{~km}$ with the ancient distance of 100 Roman miles, we arrive at the figure of $1600 \mathrm{~m}$ per mile.

77 We suppose that some short overland distances leading to such outliers could be explained by the inclusion of routes defined by specific landscape features (e.g. around a mountain).

78 The group around this value may have originated either from distances which were estimated in the itinerary Roman miles or from the Greek cartographical distances measured in the itinerary stades and recalculated into the Roman miles according to the 'common rule' 1: 8. In fact, with this ratio the Roman mile of $1200 \mathrm{~m}$ would correspond to a length of the stadion equal to $1200 / 8=150 \mathrm{~m}$.

79 We assume that some short oversea distances which lead to this small value involve routes around islands. Otherwise, such mistakes would hardly have been left uncorrected by Pliny, who was a naval officer. 

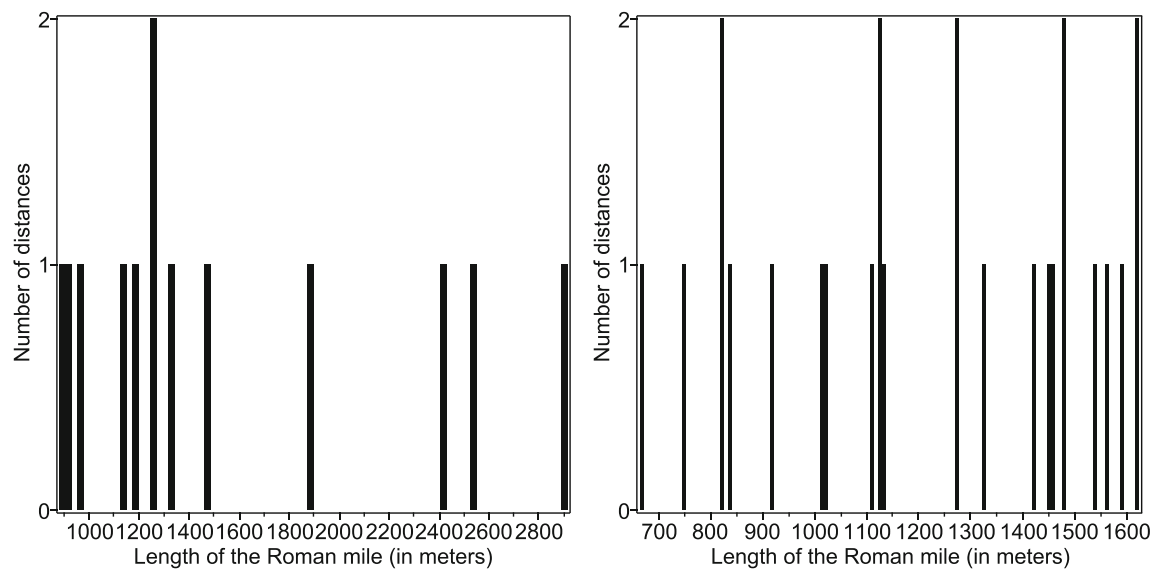

Fig. 3 Length of the Roman mile derived from Pliny's oversea distances. Left: distances under (or equal to) 125 Miles. Right: distances over 125 Miles

number of well-estimated distances with a length of the Roman mile close to $1480 \mathrm{~m}$. The 'weighted' mean length of the Roman mile, calculated by Shcheglov for the set of data over 250 miles as $1196.1 \mathrm{~m}$, not only fails to show the 'trend' but also reveals a significant gap in the distribution of values. One can see how misleading a conclusion can be if it is based on a sample inappropriately small for statistical analysis.

We conclude that Shcheglov's claim of an average 'overestimation' of Roman distances by $25-30 \%$ is not valid. Of course, for the routes which have not been reduced for their deviation from the shortest distances between the locations, we can expect some variation, and it was in fact estimated in antiquity at ca. $30 \%$. For example, Ptolemy often reduced the length of the distances used in his cartographical work by one third. But as Figs. 2-3 show, the distances transmitted by Pliny were of a mixed character and clearly included groups with different origins, not only the 'straight line' routes - and only this last set of data results in an accurate length for the Roman mile.

Let us now turn to the ancient Greek distances. First, of Eratosthenes' two maritime distances considered by Shcheglov, one had to be rejected - this is the distance between Alexandria and Rhodes given by Shcheglov as 4000 stades. We know from Strabo's remark (Strabo 2.5.24) that Eratosthenes claimed to have found the distance between these locations to be 3750 stades 'using the shadow of a gnomon', and that there were others who estimated it as 4000 or even 5000 stades. Thus, we have a single distance between Cape Phucus and Kriometopon resulting in a length of the stadion equal to $158.07 \mathrm{~m}$.

To quantify Eratosthenes' overland distances, we will start once again with a simple visualization of the data distribution. Figure 4 shows the lengths of the stadion (extracted from Shcheglov's EXCEL table) for Eratosthenes' overland distances vs. number of distances (left) and the same vs. the length of distances (right). ${ }^{80}$

\footnotetext{
80 We have excluded from the data set for the overland distances those along the rivers (as Shcheglov also did).
} 

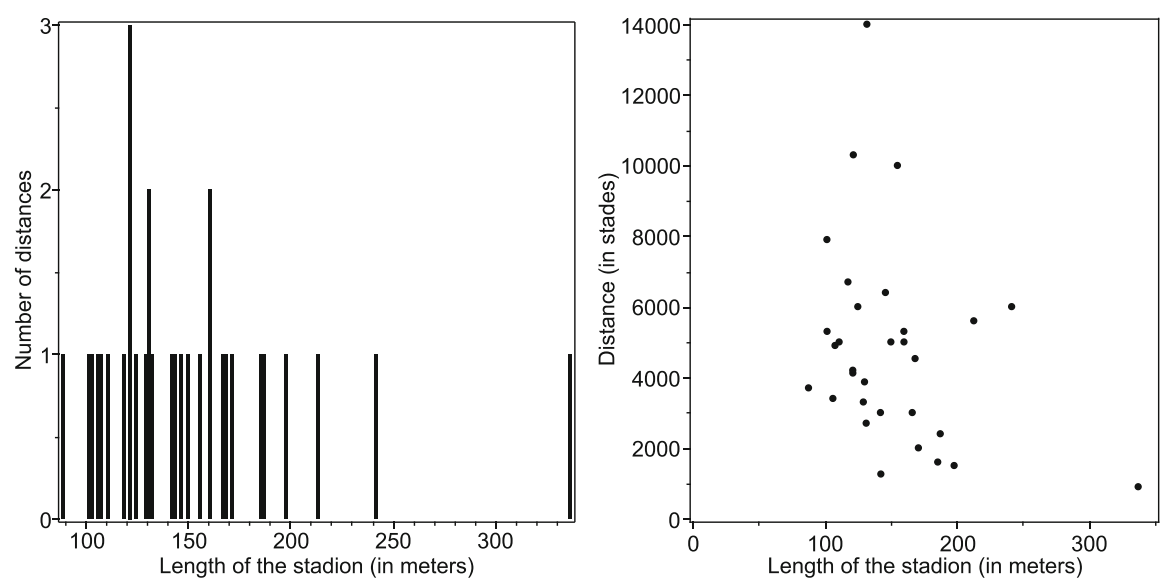

Fig. 4 Length of the stadion derived from Eratosthenes' overland distances

Without the outlier on the right-hand side of the histogram, ${ }^{81}$ the data set given at Fig. 4 (left) follows - according to the Shapiro-Wilk test-a normal distribution with the simple mean of $144.5 \mathrm{~m}$ for the stadion, but we are certainly facing here the limits of statistical analysis based upon only a few data. In fact, the calculated lengths of the stadion show two clusters-one centred around $160 \mathrm{~m}$ and the second around $125 \mathrm{~m}$. This pattern of distribution may point to two different modes of estimating distances, e.g. by bematists and by merchants who accompanied caravans. Figure 4 (right) highlights also that the majority of long distances over 6000 stades (e.g. 14,000 stades between the Indus at the mouth of the Kabul river and the Caspian Gates, 10,000 stades between the Indus at the mouth of the Kabul river and Palimbotra) are mainly expressed in the itinerary stades. ${ }^{82}$

For the analysis of Strabo's overland distances, we have divided the data into two categories: under (or equal to) 1000 stades, and over this limit. The results are shown in Fig. 5.

One can clearly see different patterns of the results for the short (Fig. 5, left) and the long distances (Fig. 5, right). ${ }^{83}$ The longer distances show some clustering between 100 and $110 \mathrm{~m}$, a cluster near the length of the itinerary stadion at around $150 \mathrm{~m}$ (similar to the distribution of Eratosthenes' data), but also a group around $187 \mathrm{~m}$ which may have originated from distances measured in the Roman miles and recalculated into stades according to the 'common rule' 1: 8; the whole set does not follow a normal distribution. For this data set, Shcheglov has calculated the 'weighted' length of the

\footnotetext{
81 Corresponding to a length of the stadion equal to $337.3 \mathrm{~m}$, based upon the distance between Epidamnus and Thessaloniki.

82 Figures 1, 2, 3, 4 given by Shcheglov (2018) for the length of the stadion vs. 'distances added accumulatively' are considered by the current author to be misleading because an attribution of a single value for a length of the stadion to a single 'accumulated' distance is deeply problematic: e.g. 1000 stades can be obtained in various way-as $500+500$ or as $300+700$ stades for example. Thus, the dotted curves on these graphs reflect the order in which the lengths of the stadion were given in the EXCEL tables.

83 Notice the different scales on the axes.
} 

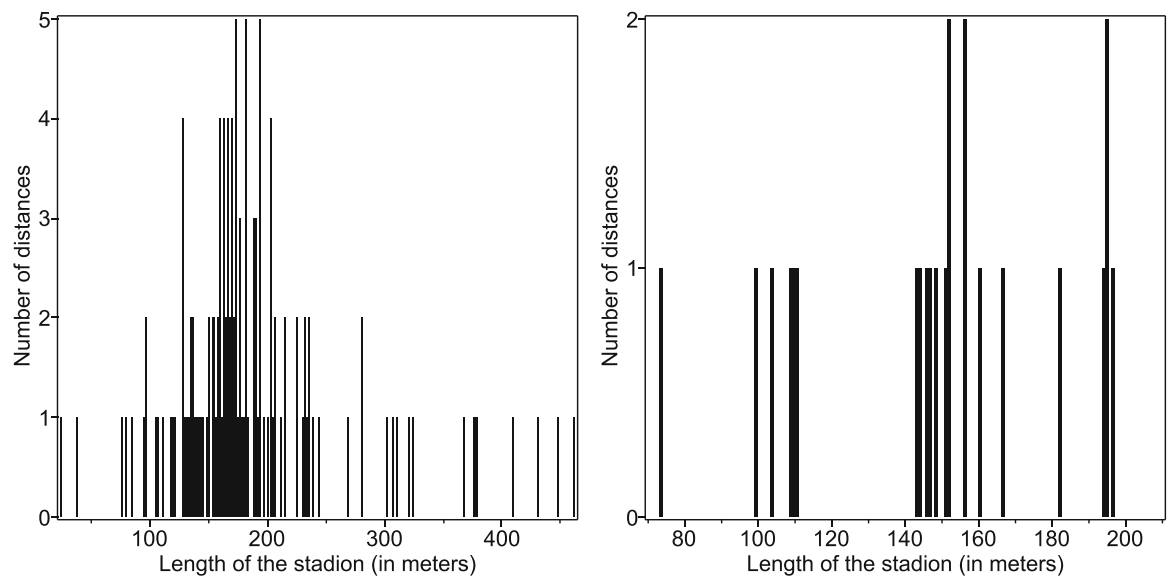

Fig. 5 Length of the stadion derived from Strabo's overland distances. Left: distances under (or equal to) 1000 stades. Right: distances over 1000 stades

stadion as $148.2 \mathrm{~m}$, but this figure obviously does not reflect all the complexity of the data.

The data set for the distances under 1000 stades (rejected in the analysis of Shcheglov) is much bigger. One can try to apply here the robust statistical methods that are not unduly affected by outliers and calculate (instead of the mean value) the median value as a more robust measure of central tendency and also the winsorized mean. ${ }^{84}$ Although the whole data set does not follow a normal distribution, one can refine the whole set to separate out such anomalous data by progressively excluding the outliers. The resulting normally distributed sets have (depending on the confining criteria) a winsorized mean of about $172 \mathrm{~m}$. Thus, we can only conclude that Strabo's overland distances under 1000 stades had a mixed character: some of them were transmitted in itinerary stades but many originated from Roman sources recalculated into stades.

Let us now consider Strabo's oversea distances (Fig. 6). For the longer distances (Fig. 6, right), we can infer a pronounced clustering of the data around the length of the itinerary stadion with only a few values outside this range. The whole set of oversea distances over 1000 stades satisfies the Shapiro-Wilk test for normal distribution with a winsorized mean of $140.2 \mathrm{~m}$. The clearly separated cluster around the length of the itinerary stadion in the middle of the graph corresponds to the winsorized mean of $135 \mathrm{~m}$ with a relatively small standard deviation of only $11.9 \mathrm{~m}$. The remarkable uniformity of this cluster points towards a set of data going back to some cartographical tradition with accurately calculated and adjusted lengths of the routes.

In contrast, for the oversea routes under 1000 stades (Fig. 6, left), once more rejected by Shcheglov, the situation is more complicated. Some distances seem to have been extracted from the old data of Eratosthenes (or from the same cartographic tradition)

\footnotetext{
84 This procedure involves the calculation of the mean after winsorizing-replacing given parts of a probability distribution or sorted sample at the high and low end with the most extreme remaining values, typically doing so for an equal number of both extremes; often 10-25 percent of the ends of the distribution are replaced. All the following results were obtained with the Statistics package of MAPLE.
} 

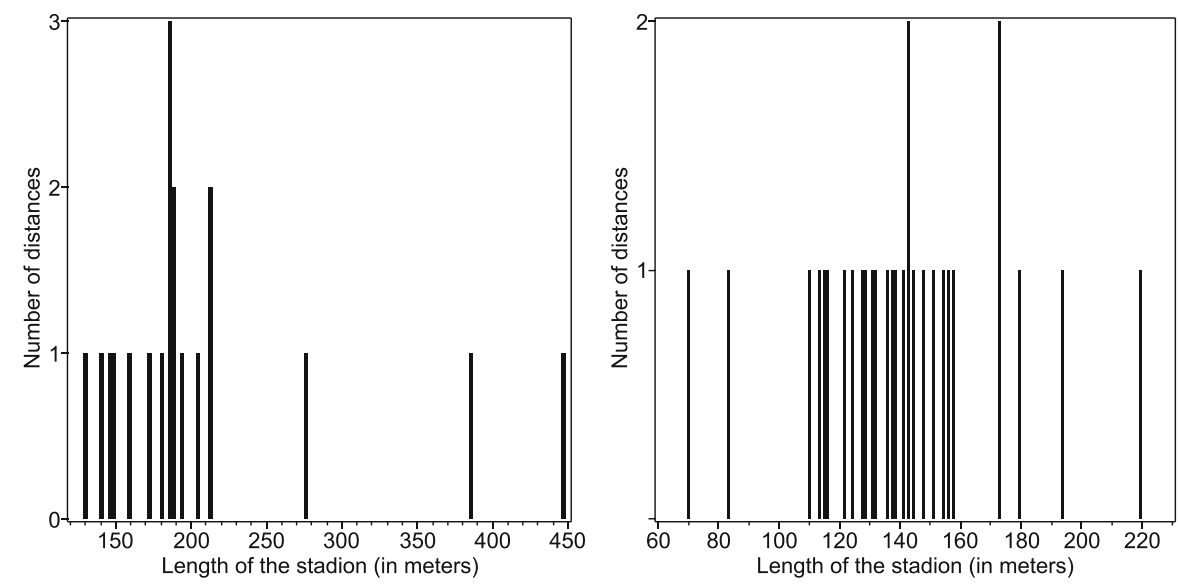

Fig. 6 Length of the stadion derived from Strabo's oversea distances. Left: distances under (or equal to) 1000 stades. Right: distances over 1000 stades

and measured in the itinerary stades but some definitely cluster around the value of $185 \mathrm{~m}$ and may go back to the recalculation of Roman distances into stades.

The simple comparison of data displayed in Figs. 1, 2, 3, 4, 5, 6 shows how misleading an attempt to describe the whole spectrum of ancient distances with a single mean value can be. Such a simplistic statistical approach would require treating them all as normally distributed and discounting their often mixed character.

\section{Special case: Ptolemy's "Geography”}

For a representative statistical analysis, we need significantly more data than have been preserved and attributed to Eratosthenes and Strabo. It is therefore very tempting to use our major geographical source-Ptolemy's catalogue of toponyms given in his Geography (ca. AD 150) with its more than 6300 pairs of coordinates expressed in degrees of latitude (counted from the equator) and longitude (counted from the Insulae Fortunatae/Canary Islands-Ptolemy's Prime Meridian). Why not calculate all the possible mutual distances between the identified localities ${ }^{85}$ in this catalogue and apply statistical methods to this really 'big data' set? Another advantage of using Ptolemy's catalogue would be that to establish the set of geographical coordinates, Ptolemy should have had to reduce the known distances to the arcs of the great circles - and those are exactly what we need to estimate the length of a stadion. ${ }^{86}$ Nevertheless, we

\footnotetext{
85 Ptolemy gives coordinates of 6345 locations and additionally names 1404 localities without coordinates (Stückelberger 2009: 241; Stückelberger and Graßhoff 2006). Provided that all the locations were identified, we would obtain more than 19 million mutual distances.

86 What Ptolemy had at his disposal to recalculate the distances measured along the arcs of the great circles into degrees were his table of chords and different modifications of Menelaus' theorem. About this theorem see, for example, Neugebauer (1975: 21-30).
} 
Table 2 Length of the stadion and the circumference of the Earth by Eratosthenes and Ptolemy

\begin{tabular}{lllll}
\hline & Length of the stadion & $1^{\circ}$ in stades & $1^{\circ}$ in $\mathrm{km}$ & $\begin{array}{l}\text { Circumference of } \\
\text { the Earth }\end{array}$ \\
\hline Eratosthenes & 157.5 & 700 & 110.25 & 39,690 \\
& 185 & 700 & 129.5 & 46,620 \\
\multirow{2}{*}{ Ptolemy } & 157.5 & 500 & 78.75 & 28,350 \\
& 185 & 500 & 92.5 & 33,300 \\
Actual & & & 111.1 & 40,000 \\
\hline
\end{tabular}

cannot directly use the Ptolemaic data and we will now explain the background to the problem.

We know that latitudes were known from astronomical observations only for a small number of the locations and were based mostly on equinoctial gnomon shadows which could be directly recalculated in degrees. And only in very rare cases, were the longitudinal distances between pairs of locations known in hours (e.g. through the simultaneous observation of lunar eclipses ${ }^{87}$ ), and recalculated in degrees according to the ratio $24 \mathrm{~h}=360^{\circ}$. If the information used by Ptolemy were gained from astronomical observations only, i.e. from measured angles, he would have been able to construct his system of geographical coordinates in the direct way. Unfortunately, for the majority of the locations, Ptolemy had at his disposal only the terrestrial distances measured in different units (stadia, miles, schoeni, etc.) or given as travel times. To construct a coherent system of geographical coordinates, Ptolemy had performed a huge amount of work to adjust these distances to each other. For short distances he could start with a plane coordinate system, but for distances longer than, let us say, $100 \mathrm{~km}$, he had to use ab initio a spherical coordinate system. The final product became heavily dependent upon Ptolemy's decision to equate 500 stades to $1^{\circ}$, i.e. to define the circumference of the Earth as $500 * 360=180,000$ stades. This is why-contrary to common sense - the size of the Earth is so crucial for the genesis of Ptolemy's catalogue.

Table 2 shows the circumference of the Earth for Eratosthenes and Ptolemy for two values of the stadion discussed in this text. Obviously, Eratosthenes' Earth is too big when the length of the stadion is equal to $185 \mathrm{~m}$, but for a stadion equal to $157.5 \mathrm{~m}$ Eratosthenes' result matches the actual circumference very well. By Ptolemy's reckoning, in both cases, the size of the Earth is too small. This crucial error significantly distorts Ptolemy's cartography ${ }^{88}$ and inevitably compromises the results of any statistical analysis.

\footnotetext{
87 Ptolemy gives an example in Geography 1.4.2: this is the famous lunar eclipse observed simultaneously at Arbella and at Carthage.

88 For problems of Ptolemy's cartography and possible mathematical solutions see Tupikova (2014). The cartographical consequences of the erroneous mapping performed by Ptolemy are responsible for, e.g. doubling of positions, their inversion, or the phenomenon of 'overmapping' when a position on a local map is adjusted to a distant position from another local map. For a mathematical explanation see Tupikova et al. (2014: 63-67).
} 
A simple consideration highlights the importance of the presumed circumference of the Earth for construction of the catalogue of geographical coordinates. Let us assume, for example, that the length of Ptolemy's stadion was equal to $185 \mathrm{~m}$. Then, the distance of $500 \mathrm{~km}$ along a great circle at the Earth's surface would correspond on Ptolemy's map $^{89}$ to $500 \mathrm{~km} * 360^{\circ} / 33300 \mathrm{~km} \cong 5.4^{\circ}$. In reality, this distance should correspond on the map to $500 \mathrm{~km} * 360^{\circ} / 40000 \mathrm{~km}=4.5^{\circ}$ only and a map constructed with the help of Ptolemy's coordinates would look overextended. For a stadion of $185 \mathrm{~m}$ this 'stretching coefficient' amounts to $40,000 / 180000 * 0.185 \cong 1.2$ and for a stadion of $157.5 \mathrm{~m}$ the stretching coefficient amounts to ca. 1.4. That the erroneous size of the Earth must be the main reason for the overextension of the Ptolemaic maps in the east-west direction ${ }^{90}$ was previously understood by some scholars, e.g. by P. F. J. Gosselin (1790: 121ff.), ${ }^{91}$ W. D. Cooley (1854: 45-46) and H. F. Tozer (1897: 341-342). One can only wonder why such a simple idea (although not elaborated thoroughly with all its mathematical consequences) has not yet become the scientific paradigm in modern Ptolemaic studies.

The length of the 'Ptolemaic' stadion deduced from the statistically determined 'stretching coefficient' was published by L. Russo in 2013. It was based on the following idea. Let $\Delta \lambda$ Ptolemy be the difference in longitude between two locations according to Ptolemy, while $\Delta \lambda_{\text {modern }}$ is their actual longitudinal difference. Let $\mathrm{d}_{\mathrm{m}}$ be an arc of equator between the meridians of these two locations in meters and let $d_{s t}$ be the same in stades, respectively. Because at the equator the length of $1^{\circ}$ is approximately $111.1 \mathrm{~km}$, and because we know that Ptolemy attributed to $1^{\circ}$ a value of 500 stades, we derive the value of the stadion in meters as:

$$
\text { Length of the stadion }=\frac{d_{m}}{d_{s}}=\frac{111100}{500} * \frac{\Delta \lambda_{\text {modern }}}{\Delta \lambda_{\text {Ptolemy }}} .
$$

By replacing $\Delta \lambda_{\text {modern }} / \Delta \lambda_{\text {Ptolemy }}$ with its mean value given by the regression coefficient $1 / 1.428$ (i.e. the inverse of the 'stretching coefficient' $=1.428$ ) gained through the numerical comparison of ca. 80 Ptolemaic longitudes with the true longitudes of identified locations, Russo estimated the statistical mean value of the stadion to be $155.6 \mathrm{~m}$.

Clearly, this method is a rough oversimplification. First, such an approach is equivalent to the assumption that the overextension of a route in Ptolemaic coordinates is proportional to the overextension in longitude. This is simply wrong. Secondly, it is obvious that only a handful of positions were adjusted by Ptolemy on his map relative to his Prime Meridian. The majority of the positions were adjusted to the locations whose coordinates were already distorted in various ways. A simple numerical test

\footnotetext{
89 By 'map' we mean here the set of Ptolemy's geographical coordinates projected onto the surface of the sphere. It is a disputable matter whether Ptolemy himself supplied his book with maps.

90 The overextension in the north-south direction is partly constrained by some known latitudes.

91 The author tried to 'correct' Ptolemy's coordinates by changing Ptolemy's longitudes. Multiplying them by the factor of 500/700 stades per degree, he tried to explain in this way the stretching of the Ptolemaic map in the east-west direction. Simultaneously, Gosselin assumed that Ptolemy inherited from Eratosthenes the length of one degree along a meridian as 700 stades-but such a suggestion automatically implied an elliptical form of the Earth. This salient result was overlooked not only by Gosselin himself but also by Shcheglov (2016a: 693) who attributes to Gosselin the "convincing recalculation' of Ptolemy's coordinates".
} 
can show that the 'stretching' coefficient (and, therefore, the length of the stadion) depends upon the eastern or western adjustment of a location. ${ }^{92}$ The small deviations from the mean value of the digression coefficient obtained by L. Russo were a lucky coincidence of his choice of famous localities along a small belt of latitudes, the majority of which linked most probably with Alexandria, the native city of Ptolemy. ${ }^{93}$

Recently D. Shcheglov (2016b) in his paper on the longitudinal errors in Ptolemy' Geography tried to extend this analysis to other localities by dividing a set of Ptolemaic coordinates into 9 groups and calculating the 'stretching coefficient' for every group separately. The resulting figures varied between 1.1478 and 2.1083 and corresponded to a length of the stadion between 194 and $105 \mathrm{~m} .{ }^{94}$ In our opinion, this study demonstrates exactly the problems of Russo's algorithm combined with the distorted topology of Ptolemy's local maps.

In principle, the Ptolemaic relation 500 stades $=1^{\circ}$ allows us to calculate the mutual distance for every pair of the Ptolemaic locations in stades in the following way: using the geographical coordinates of two locations from Ptolemy's catalogue, we can calculate the mutual distance in degrees and then multiply the result by 500. Although it is obvious that not all distances recovered in this way represent the distances known to Ptolemy and used by him in constructing his catalogue, it is a common mistake to assume that the length of Ptolemy's stadion can be obtained by directly comparing all Ptolemy's data with the actual distances. ${ }^{95}$

So far, in the course of our discussion, we have presented some common-sense arguments. The following consideration is, however, not so obvious and it needs to be discussed here in more detail. The most important point is as follows: The direct comparison of a distance between points A and B, calculated with the help of Ptolemy's coordinates, with its modern counterpart or with the same distance transmitted in other ancient sources, makes sense only under one specific condition: One must be sure that Ptolemy put point $\mathrm{B}$ on his map directly relative to point $\mathrm{A}$.

We will now clarify this statement. Let us assume that some location $\mathrm{A}_{1}$ on Ptolemy's map with already firmly established coordinates was used to adjust two other locations, let us call them $B_{1}$ and $C_{1}$. If the distances $A_{1} B_{1}$ and $A_{1} C_{1}$ were known to Ptolemy and directly used by him for constructing the coordinates of $\mathrm{B}_{1}$

\footnotetext{
92 The numerical example will be given later in this text.

93 That Alexandria was one of the most important reference points for Ptolemy is clear, for example, from Geography 8.3-8.23 where the longitudinal differences (in hours) are given relative to this city.

94 Although Shcheglov (2016b: 6) seems to understand that "Most of distances known to ancient geographers were oriented at an angle to the grid of parallels and meridians. Therefore, the recalculations of these distances would have produced a longitudinal displacement with the factor less than 1.4, because the factor of 1.4 is valid only for distances along parallels (i.e. longitudinal intervals)", he nevertheless fully ignores the problem in all his calculations. It is clear why the stretching coefficients and the 'statistical lengths' of the stadion resulting from Shcheglov's analysis are all different-the sets of Ptolemy's distances were merely adjusted to the different reference points, under different angles and in different directions (to the east or to the west of the reference point). Shcheglov's results were unfortunately taken for granted by Russo (2018).

95 Or that the relation of Ptolemy's stadion to the Roman mile can be obtained by comparing Ptolemy's data with the distances in Roman miles recorded in itineraria. For eample, Shcheglov (2016a: 700) claims that “...the only reliable way to determine the length of Ptolemy's stade is to find close enough and statistically significant correspondence between his map and distances recorded by other sources in Roman miles, which would give us the ratio between Ptolemy's stade and the mile".
} 
and $\mathrm{C}_{1}$, we will call them primary distances. Now, we can calculate the corresponding distances $A_{1} B_{1}, A_{1} C_{1}$ and $B_{1} C_{1}$ in stades with the help of Ptolemy's catalogue.

Provided the Ptolemaic locations $\mathrm{A}_{1}, \mathrm{~B}_{1}$ and $\mathrm{C}_{1}$ are correctly identified as the locations $\mathrm{A}, \mathrm{B}$ and $\mathrm{C}$ on the modern map, we can calculate the corresponding actual distances $\mathrm{AB}, \mathrm{AC}$ and $\mathrm{BC}$. We can try to find out the stretching factor due to the underestimated circumference of the Earth. Let us assume, for example, that we have calculated it to be $\mathrm{A}_{1} \mathrm{~B}_{1} / \mathrm{AB}=1.4$ and $\mathrm{A}_{1} \mathrm{C}_{1} / \mathrm{AC}=1.4$. It may not be obvious, but -in contrast with the plane trigonometry and against human intuition based on the 'local plane' experience- the stretching factor for the distance $\mathrm{B}_{1} \mathrm{C}_{1} / \mathrm{BC}$ will not be equal to 1.4. Therefore, the resulting length of the stadion calculated for the distance $\mathrm{B}_{1} \mathrm{C}_{1}$ will differ from the result for the routes $A_{1} B_{1}$, and $A_{1} C_{1}$. The problem is that the distance $\mathrm{B}_{1} \mathrm{C}_{1}$ was not known and used in the mapping, but appeared simply as a result of adjusting $B_{1}$ and $C_{1}$ to $A_{1}$. We will call such distances the secondary distances.

Figure 7 explains this result. Let us consider a spherical triangle $\mathrm{ABC}$ (left) at the surface of the real Earth which will be mapped as a triangle $A_{1} B_{1} C_{1}$ on the 'Ptolemaic' Earth (right). Let us assume that $\mathrm{A}_{1} \mathrm{C}_{1}=1.4 \mathrm{AC}$ and $\mathrm{A}_{1} \mathrm{~B}_{1}=1.4 \mathrm{AB}$. The side $\mathrm{B}_{1} \mathrm{C}_{1}$ in this triangle can be calculated with the help of the spherical law of sines:

$$
\frac{\sin \mathrm{B}_{1} \mathrm{C}_{1}}{\sin \alpha}=\frac{\sin \mathrm{A}_{1} \mathrm{C}_{1}}{\sin \beta_{1}}=\frac{\sin \mathrm{A}_{1} \mathrm{~B}_{1}}{\sin \gamma_{1}}
$$

after computing the angles $\beta_{1}$ or $\gamma_{1}$. It can be proved mathematically that the ratio $\mathrm{B}_{1} \mathrm{C}_{1} / \mathrm{BC}$ will not be equal to 1.4 but will depend upon the size of the spherical triangle and its orientation.

We will formulate this very important result as.
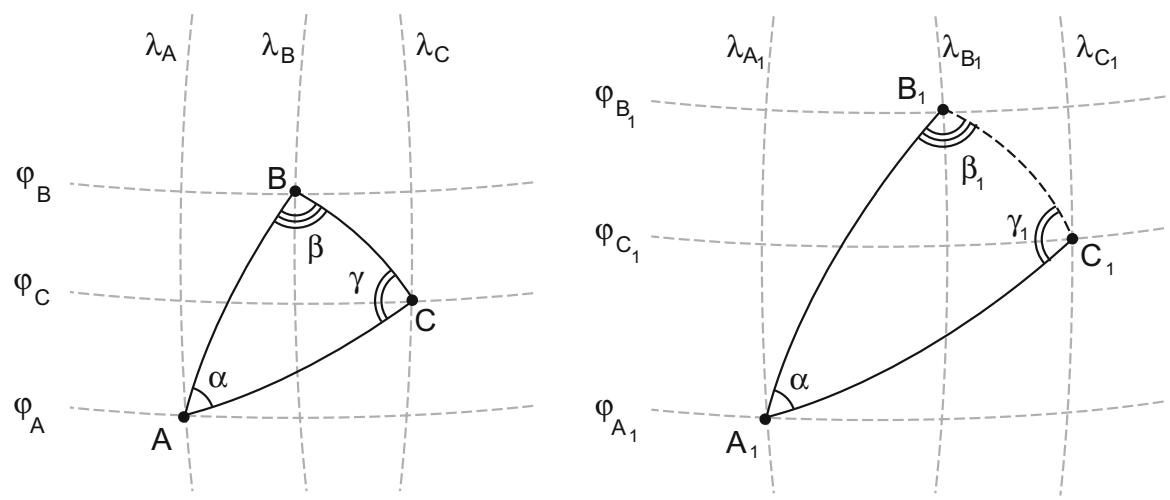

Fig. 7 Problems in calculation of stretching coefficients for Ptolemaic distances. Left: surface of the true Earth. Actual positions of the locations A, B and C build up the spherical triangle ABC. Right: surface of the Ptolemaic Earth. The triangle $\mathrm{ABC}$ will be displayed as the spherical triangle $\mathrm{A}_{1} \mathrm{~B}_{1} \mathrm{C}_{1}$ with the arcs $A_{1} B_{1}$ and $A_{1} C_{1}$ bigger than $A B$ and $A C$. The proportion of the overextension will not be the same: If $\mathrm{A}_{1} \mathrm{~B}_{1} / \mathrm{AB}=1.4$, and $\mathrm{A}_{1} \mathrm{C}_{1} / \mathrm{AC}=1.4$, nevertheless, $\mathrm{B}_{1} \mathrm{C}_{1} / \mathrm{BC}$ will not be equal to 1.4 
Conclusion 4 The numerical analysis of the Ptolemaic distances gained from his catalogue of locations makes sense only for distances directly known and used by Ptolemy in calculating the geographical coordinates.

Historical sciences are becoming increasingly computerized, and the advantages of storage and usage of information in digitized form facilitate the routines of historians. Ptolemy's catalogue of geographical positions, explicitly designed to be 'user-friendly' ( $\varepsilon$ u’ $\rho \eta \sigma \tau o \nu)$, seems to be a prime example for IT-related approaches (Ptolemy, Geography $1.6 .2 ; 1.18 .2 ; 2.1 .4)$. But computer programs designed for statistical analysis of different data sets cannot be directly applied to the distorted cartography of the Ptolemaic maps-they will inevitably produce erroneous results unless they classify Ptolemaic data into primary and the secondary distances. But how can we be sure that a certain distance was known and directly used by Ptolemy?

An educated guess would be to assume that distances adjusted by Ptolemy relative to his famous 'cornerstones'/themelioi (Ptolemy Geography 1.4.2; see also Heß 2013) can be considered as primary distances.

Let us look once more at the distance between Alexandria and Syene. Ptolemy gives us for these locations the following coordinates: Alexandria- $31^{\circ} \mathrm{N}, 60^{\circ} 30^{\prime}$ and Syene-23 $-20^{\circ} \mathrm{N}, 62^{\circ},{ }^{96}$ (both longitudes are counted from the Insulae Fortunatae; the difference in longitudes shows that Ptolemy already knew that these locations do not lie on the same meridian). The distance between these locations calculated in degrees from the Ptolemaic coordinates measures ca. $7.28^{\circ}$. With $1^{\circ}=500$ stades this corresponds to 3640 stades, thus contradicting the standard ancient estimation of this distance as 5000 stades. Can this result be used as an argument in the eternal discussion about the length of Ptolemy's stadion? Certainly, it does not support the figure of $185 \mathrm{~m}$ (with this length of the stadion, 3640 stades would correspond to ca. $673 \mathrm{~km}$ ). How could this distance be so hugely underestimated in comparison with the actual distance of $845 \mathrm{~km}$ ? Measured in the 'itinerary' stades, Ptolemy's distance would be even smaller: $3640 * 157.5 \mathrm{~m}$ is ca. $573 \mathrm{~km}$. The answer to this mysterious problem lies in Ptolemy's circumference of the Earth. If adopted, Eratosthenes' circumference of the Earth (i.e. the relation $1^{\circ}=700$ stades) would have led to a distance equal to $7.28 * 700=5096$ stades - that is, very close to the ancient estimation. Another famous location, Meroe, is placed by Ptolemy at $16^{\circ} 25^{\prime}$ latitude and $61^{\circ} 30^{\prime}$ longitude-that is, between the meridians of Alexandria and Syene. The distance between Syene and Meroe calculated from Ptolemy's coordinates amounts to $7.43^{\circ}$ and corresponds to $7.43 * 500=3715$ stades and we face here a similar problem - this distance was estimated in antiquity as the same 5000 stades. Once more, multiplying Ptolemy's angular distance between these locations by Eratosthenes' estimation of $1^{\circ}$ as 700 stades we came close to the ancient estimation: $7.43 * 700=5201$ stades. In fact, the latitudes of Alexandria, Syene and Meroë constituted in antiquity a part of the scientific paradigm and Ptolemy had

\footnotetext{
96 Geography 4.5.9 and 4.5.73, respectively. In his Almagest 5.2, Ptolemy gives the obliquity as $23^{\circ} 51^{\prime}$. In Geography 1.23.7, he emphasizes that Syene is situated exactly below the summer tropic and gives its distance to the equator as $23^{\circ} 50^{\prime}$. The mean ecliptic in Ptolemy's time varied between $23^{\circ} 40^{\prime} 58^{\prime \prime}$ and $23^{\circ} 40^{\prime} 26^{\prime \prime}$.
} 
to place them on the proper latitudes and approximately along the same meridian ignoring (and perhaps not even recognising) the resulting mutual distances. ${ }^{97}$

We consider that exactly these strange distances calculated between the locations along the most famous ancient meridian Alexandria-Syene-Meroe are strong evidence for the idea that many ancient and/or Eratosthenes' distances were taken for granted by Ptolemy and used in constructing his catalogue of coordinates by recalculating them into degrees according to the rule by which 500 stades are equal to $1^{\circ}$. How could one confirm or discard this assumption?

One can tackle this problem in the following way: what we know for sure is that for Eratosthenes, one degree on the Earth's surface was equal to 700 stades and for Ptolemy equal to 500 stades. Now we can consider two cases: a) the length of the stadion used by Ptolemy and by Eratosthenes was the same or b) they used different stades. Let us assume first that both scholars used stades of the same length (case ' $a$ '). Then, the coordinates given in Ptolemy's Geography can be transformed from a sphere with a circumference of 180,000 units to a sphere with a circumference of 252,000 units and such a transformation does not require any assumption about the length of the stadion ${ }^{98}$ - it can be $157.5 \mathrm{~m}$ or $185 \mathrm{~m}$ or any other disputable figure. Provided that the scholars used different stades (case ' $b$ '), we can assume, for example, that Ptolemy's stadion was equal to $185 \mathrm{~m}$ and Eratosthenes' distances were measured in the itinerary stades. In this case, one can transform Ptolemaic coordinates from a sphere with a circumference of $180,000 * 185 / 157.5$ units to a sphere with a circumference of 252,000 units. Of course, not all the coordinates (and, accordingly, not all the mutual distances) are suitable for the analysis: because of the problem discussed above one should choose the primary distances related to the certain themelioi.

Now, comparison of the transformed Ptolemaic coordinates with the modern coordinates of the firmly identified locations can confirm the assumption about the equality of Ptolemy's and Eratosthenes' stadion or, alternatively, provide information about the ratio of the lengths of their respective stades. Provided that we obtain for the case 'a' a significant match of the recalculated angular coordinates with their actual counterparts, we can conclude that (1) Eratosthenes' figure of 252,000 stades is close to the actual circumference of the Earth, and therefore, (2) the length of Eratosthenes' stadion was close to the length of the itinerary stadion. As useful additional information, we can obtain for every local map a network of distances all measured relative to a special reference point and expressed in itinerary stades. This approach was first proposed and

\footnotetext{
97 As a consequence, the alignment of some positions along the Arabian Gulf to Alexandria and Syene partially resembles a modern map, although some distances-even such important ones as the distance between Adulis and Aromata - are still expressed in angular measure according to Ptolemy's 'standard' rule of $1^{\circ}=500$ stades. W. D. Cooley (1854: 46), who intuitively understood the intricacies of Ptolemy's mapping, has formulated this problem in the following way: "His map of Africa may be compared to a square handkerchief, with a knot at one corner which prevents its uniform and symmetrical expansion. The knot or contraction lay in the valley of the Nile. Egypt was comparatively well surveyed and measured, and observations of latitude, approaching to correctness, had been made at Syene and Meroe. Hence it is that, on the western side of this valley, we see exhibited, in the most glaring deformity, the discrepancy of the geographical elements brought into juxtaposition".

98 In order to transform the spherical coordinates from a sphere of one size to a sphere of another size one can use the formulae of spherical trigonometry which provide an appropriate modern algorithm to recalculate positions given in the geographical coordinate system.
} 
realized in Tupikova and Geus (2013) and Tupikova (2014). Examples of these calculations for selected positions in Central Europe (including Germania Magna) for the positions along the Silk Road to Serike and along the coastline of the Black Sea with (Ps.-) Arrian's Periplus Ponti Euxini (Geus and Tupikova 2013, 2014; Tupikova et al. 2014; Geus and Tupikova in press) show that many of Ptolemy's basic locations would have matched their modern counterparts remarkably well, if Eratosthenes' figure for the circumference of the Earth and the same length of the stadion had been adopted. ${ }^{99}$

Shcheglov (2016a) tried to explain these results differently: he assumed that the distances used by Ptolemy to construct his catalogue were steadily overestimated "by at least $20 \% " .100$ This argument is, however, factually flawed: Ptolemy's catalogue was based upon the terrestrial distances which were already curtailed by the scholar to represent the arcs of the great circles (numerous examples of principal distances which were shortened by Ptolemy are given in the first book of his Geography). ${ }^{101}$ Normally, the reduction amounted to one third of a whole route and, for example, more than a half of the route towards Sera Metropolis, as discussed in Geography 1.12.1. If Shcheglov's assumption were true, it would mean that the distances used by Ptolemy were initially overestimated by more than $70 \% .{ }^{102}$ Thus, "an alternative and more plausible explanation for the spectacular accuracy of Ptolemy's coordinates recalculated for Eratosthenes' Earth" is based upon a trivial logical mistake and can be rejected.

In conclusion, we give an example which illustrates the main problem of the statistical analysis of Ptolemy's distances.

Let us assume (and it is highly probable) that distances and directions in Germania Magna were estimated relative to the capital of the province Germania Inferior-Colonia Claudia Ara Agrippinensium/Cologne-and that this location was used by Ptolemy as the reference point for mapping of the locations in the regions to the east of it. Then, we have here a set of primary distances directly used by Ptolemy. To highlight the problem, we will consider only the firmly identified river

\footnotetext{
99 Of course, one may argue that, among more than 6300 locations in Ptolemy's catalogue, one can always find a suitable reference point whose distance to the location in question will support recalculations to its actual geographical position. But as Tupikova and Geus have shown, Ptolemy's local maps were mainly based upon only a few reference points which were used in their recalculations: Alexandria and Rome for the Mediterranean region, Colonia Agrippinensium/Cologne (Geography 2.9.15) for Germania Magna, Crossing of the Euphrates by Hierapolis/Membidj for Sogdiana and Bactria, Stone Tower for Serike. One can hardly object to these as themelioi.

100 Shcheglov (2016a: 694): “This explains why Ptolemy's map, placed on Eratosthenes' Earth, matches modern maps remarkably closely. If the same distances, overestimated by at least 20 percent, are converted to degrees according to Ptolemy's value for the Earth's size, which was underestimated by about 17 percent, then the resulting map becomes stretched by approximately 40 percent in angular terms". This mathematically obscure statement originated from that author's assumption that the length of the stadion was equal to $185 \mathrm{~m}$.

101 See Geography 1.11.4, 1.12.1, 1.13.2, 1.13.5, 1.13.7, 1.13.8, 1.14.5.

102 Let us assume, for example, that a distance transmitted in the ancient source as 1000 stades was reduced by Ptolemy by $30 \%$ and entered the calculations of his geographical coordinates as 700 stades. To explain the longitudinal overextension of Ptolemy's map, Shcheglov had to assume that this distance was overextended by 20 percent, that is, that the true distance was equal to ca. 583 stades. This leads to the overestimation of the true distance by $(1000-583) / 583 * 100 \approx 72 \%$. This is simply not credible.
} 
Table 3 Ptolemaic vs. modern coordinates of Colonia Agrippinensium/Cologne and of some selected locations in Germania Magna

\begin{tabular}{llllll}
\hline Modern name & Ptolemaic name & Modern $\varphi \mathrm{N}$ & Modern $\lambda \mathrm{E}$ & Ptolemaic $\varphi \mathrm{N}$ & Ptolemaic $\lambda$ \\
\hline Cologne & Col. Agripp & $50^{\circ} 56^{\prime} 19^{\prime \prime}$ & $6^{\circ} 57^{\prime} 36^{\prime \prime}$ & $51^{\circ} 30^{\prime}$ & $27^{\circ} 40^{\prime}$ \\
Ems & Amisia & $53^{\circ} 19^{\prime} 32^{\prime \prime}$ & $7^{\circ} 14^{\prime} 41^{\prime \prime}$ & $55^{\circ} 00^{\prime}$ & $29^{\circ} 00^{\prime}$ \\
Weser & Visurgis & $53^{\circ} 32^{\prime} 08^{\prime \prime}$ & $8^{\circ} 33^{\prime} 56^{\prime \prime}$ & $55^{\circ} 15^{\prime}$ & $31^{\circ} 00^{\prime}$ \\
Elbe & Albis & $53^{\circ} 53^{\prime} 36^{\prime \prime}$ & $8^{\circ} 42^{\prime} 20^{\prime \prime}$ & $56^{\circ} 15^{\prime}$ & $31^{\circ} 00^{\prime}$ \\
Order/Dziwna & Suebus & $54^{\circ} 01^{\prime} 00^{\prime \prime}$ & $14^{\circ} 45^{\prime} 00^{\prime \prime}$ & $56^{\circ} 00^{\prime}$ & $39^{\circ} 30^{\prime}$ \\
Stolpe & Viadua & $54^{\circ} 35^{\prime} 20^{\prime \prime}$ & $16^{\circ} 51^{\prime} 10^{\prime \prime}$ & $56^{\circ} 00^{\prime}$ & $42^{\circ} 10^{\prime}$ \\
Weichsel & Vistula & $54^{\circ} 21^{\prime} 37^{\prime \prime}$ & $18^{\circ} 57^{\prime} 10^{\prime \prime}$ & $56^{\circ} 00^{\prime}$ & $45^{\circ} 00^{\prime}$ \\
Bernburg & Luppia & $51^{\circ} 48^{\prime} 00^{\prime \prime}$ & $11^{\circ} 45^{\prime} 00^{\prime \prime}$ & $52^{\circ} 45^{\prime}$ & $34^{\circ} 30^{\prime}$ \\
Stereontium & Bad Driburg & $51^{\circ} 44^{\prime} 00^{\prime \prime}$ & $9^{\circ} 01^{\prime} 01^{\prime \prime}$ & $52^{\circ} 10^{\prime}$ & $31^{\circ} 00^{\prime}$ \\
\hline
\end{tabular}

mouths—Suebus ${ }^{103}$ as Swine/Oder, Amisia as Ems, Visurgis as Weser, and Vistula as Weichsel and two cities-Luppia/Bernburg and Stereontium/Bad Driburg. The modern vs. Ptolemaic coordinates (Geography 2.9.15, 2.11.28, 2.11.1, 2.11.4) of these locations are given in Table 3. The distances between these localities and Cologne were calculated according to their actual geographical positions, first in degrees and then in kilometres (assuming that $1^{\circ}=111.1 \mathrm{~km}$ ). The corresponding Ptolemaic distances were calculated also first in degrees and then in stades. Comparing these results allows us to calculate for every mutual distance the corresponding 'length of the stadion'. The results for every separate route as well as average result (in bold face at the bottom of the table) are given in Table 4, top. To show the importance of the choice of the reference point—or, equivalently, the importance of the correct identification of primary distances - we have performed the same calculations relative to the easternmost mouth of the river Vistula/Weichsel. The results of this second calculation are given in Table 4 at the bottom. One can easily see that a simple change of the reference point in calculating the distances changes the resulting 'length of the stadion': for our set of data the mean length of the stadion amounts to $151.83 \mathrm{~m}$ for the distances calculated relative to Cologne (that is, adjusted to the east of the reference position), and to $168.72 \mathrm{~m}$ for the distances calculated relative to the Weichsel (adjusted to the west). The reason for such a counterintuitive result has been discussed above.

We have now shown how important the choice of the primary distances is. For the locations in the Germania Magna we were (possibly) able to make an educated guess - but this is not always the case. Can modern statistical methods used in cartography help to compensate for the lack of the historical information? An example of the statistical analysis of Ptolemy's coordinates based on the Gauss-Markov method has recently been presented by a group of German scholars (Kleineberg et al. 2010, 2012; Marx and Kleineberg 2012; Marx 2014, 2015). The aim of their study was not to determine the length of the stadion but to 'rectify' the Ptolemaic coordinates: the

\footnotetext{
103 We prefer to identify the mouth of the Suebus/Oder with its eastern mouth (Dziwna). The main reason is the absence of the Szczecin Lagoon in Ptolemy's Geography.
} 
Table 4 Errors caused by the erroneous topology of the Ptolemaic map: determination of the length of the stadion for a number of identified locations in Germania Magna. Top: the distances and the corresponding lengths of stadion are calculated relative to Colonia Agrippinensium/Cologne. Bottom: the distances and the lengths of stadion are calculated relative to Vistula/ Weichsel

\begin{tabular}{|c|c|c|c|c|c|c|}
\hline Modern name & $\begin{array}{l}\text { Ptolemaic } \\
\text { name }\end{array}$ & $\begin{array}{l}\text { Distance } \\
\text { to Cologne } \\
\text { (deg.) }\end{array}$ & $\begin{array}{l}\text { Distance } \\
\text { to } \\
\text { Cologne } \\
(\mathrm{km})\end{array}$ & $\begin{array}{l}\text { Ptolemaic } \\
\text { distance } \\
\text { (deg.) }\end{array}$ & $\begin{array}{l}\text { Ptolemaic } \\
\text { distance } \\
\text { (st.) }\end{array}$ & $\begin{array}{l}\text { Length } \\
\text { of the } \\
\text { stadion } \\
\text { (m) }\end{array}$ \\
\hline Ems & Amisia & $2^{\circ} 23^{\prime} 36^{\prime \prime}$ & 265.899 & $3^{\circ} 35^{\prime} 23^{\prime \prime}$ & 1794.795 & 148.15 \\
\hline Weser & Visurgis & $2^{\circ} 46^{\prime} 36^{\prime \prime}$ & 308.487 & $4^{\circ} 14^{\prime} 37^{\prime \prime}$ & 2121.743 & 145.39 \\
\hline Elbe & Albis & $3^{\circ} 08^{\prime} 26^{\prime \prime}$ & 348.902 & $5^{\circ} 08^{\prime} 20^{\prime \prime}$ & 2569.483 & 135.79 \\
\hline Order/Dziwna & Suebus & $5^{\circ} 39^{\prime} 03^{\prime \prime}$ & 627.803 & $8^{\circ} 18^{\prime} 09^{\prime \prime}$ & 4151.252 & 151.23 \\
\hline Stolpe & Viadua & $7^{\circ} 00^{\prime} 07^{\prime \prime}$ & 777.914 & $9^{\circ} 39^{\prime} 26^{\prime \prime}$ & 4828.551 & 161.11 \\
\hline Weichsel & Vistula & $8^{\circ} 01^{\prime} 36^{\prime \prime}$ & 891.764 & $11^{\circ} 09^{\prime} 16^{\prime \prime}$ & 5577.260 & 159.89 \\
\hline Bernburg & Luppia & $3^{\circ} 06^{\prime} 41^{\prime \prime}$ & 345.667 & $4^{\circ} 22^{\prime} 32^{\prime \prime}$ & 2187.782 & 158.00 \\
\hline \multirow[t]{2}{*}{ Stereontium } & $\begin{array}{l}\text { Bad } \\
\text { Driburg }\end{array}$ & $1^{\circ} 30^{\prime} 39^{\prime \prime}$ & 167.859 & $2^{\circ} 09^{\prime} 53^{\prime \prime}$ & 1082.400 & 155.08 \\
\hline & & & & & & 151.83 \\
\hline Modern name & $\begin{array}{l}\text { Ptolemaic } \\
\text { name }\end{array}$ & $\begin{array}{l}\text { Distance } \\
\text { to } \\
\text { Weichsel } \\
\text { (deg.) }\end{array}$ & $\begin{array}{l}\text { Distance } \\
\text { to } \\
\text { Weichsel } \\
(\mathrm{km})\end{array}$ & $\begin{array}{l}\text { Ptolemaic } \\
\text { distance } \\
\text { (deg.) }\end{array}$ & $\begin{array}{l}\text { Ptolemaic } \\
\text { distance } \\
\text { (st.) }\end{array}$ & $\begin{array}{l}\text { Length } \\
\text { of the } \\
\text { stadion } \\
\text { (m) }\end{array}$ \\
\hline Ems & Amisia & $6^{\circ} 58^{\prime} 35^{\prime \prime}$ & 775.085 & $9^{\circ} 05^{\prime} 48^{\prime \prime}$ & 4548.375 & 170.41 \\
\hline Weser & Visurgis & $6^{\circ} 09^{\prime} 46^{\prime \prime}$ & 684.676 & $7^{\circ} 55^{\prime} 34^{\prime \prime}$ & 3963.114 & 172.76 \\
\hline Elbe & Albis & $6^{\circ} 01^{\prime} 03^{\prime \prime}$ & 668.553 & $7^{\circ} 47^{\prime} 38^{\prime \prime}$ & 3896.962 & 171.56 \\
\hline Order/Dziwna & Suebus & $2^{\circ} 28^{\prime} 58^{\prime \prime}$ & 275.821 & $3^{\circ} 04^{\prime} 29^{\prime \prime}$ & 1537.375 & 179.41 \\
\hline Stolpe & Viadua & $1^{\circ} 14^{\prime} 29^{\prime \prime}$ & 137.921 & $1^{\circ} 35^{\prime} 03^{\prime \prime}$ & 792.134 & 174.11 \\
\hline Bernburg & Luppia & $5^{\circ} 01^{\prime} 26^{\prime \prime}$ & 558.158 & $6^{\circ} 54^{\prime} 57^{\prime \prime}$ & 3457.976 & 161.41 \\
\hline Stereontium & $\begin{array}{l}\text { Bad } \\
\text { Driburg }\end{array}$ & $6^{\circ} 31^{\prime} 04^{\prime \prime}$ & 724.127 & $9^{\circ} 02^{\prime} 30^{\prime \prime}$ & 4520.806 & 160.18 \\
\hline Cologne & $\begin{array}{l}\text { Col. } \\
\text { Agripp }\end{array}$ & $8^{\circ} 01^{\prime} 36^{\prime \prime}$ & 891.764 & $11^{\circ} 09^{\prime} 16^{\prime \prime}$ & 5577.260 & 159.89 \\
\hline
\end{tabular}

authors found some scaling parameters for different local maps and applied them to determine the modern coordinates of unidentified localities. Such geodetic methods to improve coordinates were, however, not designed for coordinates with a significant systematic error (in this case, caused by the erroneous size of the Earth) and cannot be applied without caution because they completely ignore the dominating role of the primary distances in the topology of the Ptolemaic maps. Our example considers only a small local map with a single reference point at Cologne. And even in this very simple case, the statistical methods failed-not due to the data set being too small, 
but due to neglecting the principal systematic error of Ptolemy's map. ${ }^{104}$ Of course, the true situation is more complicated. We can never be sure that all the distances we would like to consider in our analysis were adjusted to the same reference position-more than that, to adjust different local maps, Ptolemy had to use different reference points. $^{105}$

\section{Conclusion}

Discussing the problem of the length of the stadion, A. Diller (1949: 78) concludes:

Some light can be thrown on it, but the matter requires circumspection, and those who blithely convert in casual parentheses or footnotes are usually unaware of the difficulties and mistakes in their statements.

In this text, we did not intend to participate in the endless discussion concerning the length of the Greek stadion. Our aim was to draw attention to an aspect of this problem which can be easily overlooked by considering it from the purely metrological perspective while neglecting the common-sense point of view. By combining the two, we can obtain a clearer understanding of ancient measurement techniques and units, and formulate a convenient framework for their analysis.

It is obvious that in antiquity long distances could not have been measured with a metrical gauge, but were estimated by striding, i.e. by counting steps. Thus, the measuring unit of the distances transmitted in the itineraries was not a firm metrological unit but a variable figure strongly dependent upon the physical characteristics of the surveyors, terms and conditions of travel, and upon the terrain. Therefore, we have to strictly differentiate between the metrologically defined ancient measuring units used in building a coherent measuring hierarchy, and the itinerary units of measure. The latter belong to a 'fuzzy' measuring module with fuzzy relations between its elements. As such, the itinerary stadion cannot be defined by a single figure. Referring to the stature estimations of the ancient Greeks and Romans, we can estimate the average length of the itinerary stadion to be in the range 150-160 m, with a tendency to lower this figure when dealing with complicated terrains. This approach also explains why a stadion of $185 \mathrm{~m}$ could never have been used when measuring by striding.

We propose a simple explanation for the ratio of 1: 8 between the Roman mile and the Greek stadion based upon equating the step length in the two measuring

\footnotetext{
104 'Rectification' coefficients calculated without correction of the general systematic error of the Ptolemaic coordinates can lead to the erroneous identification of unknown locations. Let us take as an example the map of Sarmatia, where the course of the Sarmatian Ocean/Baltic sea is marked by the mouths of Chronos, Rubon, Turuntos and Chesinos (Geography 3.5.2). The statistical method applied by Kleineberg et al. (2012: 50) proposed the following identifications for the rivers: Chronos = Neman, Rubon = Daugava, Turuntos $=$ Narva River and Chesinos $=$ Neva. The reason for this historically unconvincing result lies in the attempt to apply the 'distortion coefficients' derived from Germania Magna to the adjusted region of Sarmatia. The traditional identifications of Chesinos as Pärno, Chronos as Pregolja, Rubon as Neman, and Turuntos as Daugava going back at least to d'Anville and Gosselin (Gosselin 1790: 126-127), have been vindicated in Geus and Tupikova (2013).

105 This problem, as well as all the other problems caused by the erroneous size of the Earth, is completely ignored in the latest publications aiming at a 'rectification' of Ptolemy's coordinates (Rinner 2013; Gusev et al. 2005; Abshire et al. 2016).
} 
modules - as, according to Strabo, Polybius already did-and consider this ratio to be a simple 'common agreement' figure. It was shown that for the distances measured initially in Roman miles and recalculated later into stades according to a selected ratio, the information which can be gained by comparing these distances with their actual counterparts reflects not the length of the stadion per se but the ratio used in these recalculations.

We have considered the possibility of estimating statistically the length of the itinerary stadion on the basis of distances transmitted by Strabo and of the distances attributed to Eratosthenes. It was shown that generally the data set is not representative enough to draw statistically significant conclusions. Besides that, the standard methods of statistical analysis are heavily based upon a particular assumption: the sample must show a single normal distribution with independent and random errors-and this is not the case for the data set in question. To some degree of precision, Eratosthenes' distances can be considered as normally distributed with a mean value of around $145 \mathrm{~m}$ for the length of the stadion, but Strabo's distances are of mixed character. Some of them lead to the length of the itinerary stadion (especially, long distances), but others centre around $185 \mathrm{~m}$, and could have been recalculated from the Roman distances according to the 'common' rule 1: 8 .

The special case of distances which can be calculated with the help of Ptolemy's catalogue of the geographical coordinates has been considered separately. It was shown that only the distances known to Ptolemy and directly used in the construction of his coordinates can be used for statistical determination of the length of the stadion. We have called these distances the 'primary' data. All the other distances calculated with the help of the Ptolemaic coordinates will inevitably lead to an erroneous estimation of the length of the stadion. A simple numerical example clarifies this counterintuitive statement.

The body of evidence supporting use of the itinerary stadion in antiquity considered in this paper is consistent with the principle of 'convergence of evidence' or 'consilience of inductions' principle, which states that different lines of evidence converging on a single conclusion strengthen the plausibility of an interpretation (Tucker 2008, Sect. 28). It is the convergence of evidence rather than the mere existence of some evidence that establishes the truth of a proposition.

Acknowledgements The author is indebted to the anonymous referees for many valuable suggestions and comments.

Funding Open Access funding enabled and organized by Projekt DEAL.

Availability of data and material All data generated or analysed during this study are included in this published article.

Code availability Not applicable.

\section{Declarations}

Conflict of interests Academic competing interests with D. Shcheglov.

Ethics approval Not applicable. 
Consent to participate Not applicable.

Consent for publication Not applicable.

Open Access This article is licensed under a Creative Commons Attribution 4.0 International License, which permits use, sharing, adaptation, distribution and reproduction in any medium or format, as long as you give appropriate credit to the original author(s) and the source, provide a link to the Creative Commons licence, and indicate if changes were made. The images or other third party material in this article are included in the article's Creative Commons licence, unless indicated otherwise in a credit line to the material. If material is not included in the article's Creative Commons licence and your intended use is not permitted by statutory regulation or exceeds the permitted use, you will need to obtain permission directly from the copyright holder. To view a copy of this licence, visit http://creativecommons.org/licenses/ by $/ 4.0 \%$.

\section{References}

Abshire, Corey, Dmitri Gusev, Ioannis Papapanagiotou, and Sergey Stafeyev. 2016. A Mathematical Method for Visualizing Ptolemy's India in Modern GIS Tools. E-Perimetron 11 (1): 13-34.

Arnaud, Pascal. 2011. Ancient Sailing-routes and Trade Patterns: The Impact of Human Factors. In Maritime Archaeology and Ancient Trade in the Mediterranean, ed. Damian Robinson and Andrew Wilson, 59-78. Oxford: Oxford Centre for Maritime Archaeology.

Aujac, Germaine. 1966. Strabon et la science de son temps. Les science du monde. Paris: Les Belles Lettres.

Badawy, Alexander. 1965. Ancient Egyptian Architectural Design: A Study of the Harmonic System. California: University of California Press.

Barth, Heinrich. 2020. Reisen und Entdeckungen in Nord- und Zentralafrika. 20000 Kilometer durch Afrika. 1849-1855. Wiesbaden: Edition Erdmann.

Baten, Jörg. 1999. Ernährung und wirtschaftliche Entwicklung in Bayern: (1730-1880). Beiträge zur Wirtschafts- und Sozialgeschichte 82. Stuttgart: Steiner.

Berggren, John Lennart and Alexander Jones. 2000. Ptolemy's “Geography”. An Annotated Translation of the Theoretical Chapters. Princeton/Oxford: Princeton University Press.

Borchardt, Ludwig. 1911. Altägyptische Sonnenuhren. Zeitschrift für Ägyptische Sprache und Altertumskunde 48.

Borchardt, Ludwig. 1921. Ein weiterer Versuch zur Längenbestimmung der ägyptische Meilen (itr-w). In Festschrift zu C. F. Lehmann-Haupts sechzigstem Geburtstage, eds. Kurt Regling, and Hermann Reich, 119-123. Wien/Leipzig: Braumüller.

Bowen, Alan C., and Robert B. Todd. 2004. Cleomedes' "Lectures on Astronomy”: A Translation of The Heavens. Berkeley: University of California Press.

Brugsch, Heinrich. 1867. Hieroglypisch-demotisches Wörterbuch. Leipzig: Hinrichs.

Bruins, Evert Marie (ed). 1964. Codex Constantinopolitanus. Palatii Veteris. No.1. Part 3. Translation and Commentary. Leiden: Brill.

Bunbury, Edward Herbert. 1959. A History of Ancient Geography. Among the Greeks and Romans. From the Earliest Ages Till the Fall of the Roman Empire. II. New York: Dover Publications.

Carman, Cristián Carlos., and James Evans. 2015. The Two Earths of Eratosthenes. Isis 106: 1-16.

Casson, Lionel. 1989. The Periplus Maris Erythraei: Text with Introduction, Translation, and Commentary. Princeton NJ: Princeton University Press.

Chaumont, Marie-Louise. 1984. Études d'histoire parthe V. La route royale des Parthes de Zeugma à Séleucie du Tigre d'après l'Itinéraire d'Isidor de Charax. Syria 61: 63-107.

Cimino, Massimo. 1982. A New, Rational Endeavour for Understanding the Eratosthenes Numerical Result of the Earth Meridian Measurement. In Compendium in Astronomy. A Volume Dedicated to J. Xanthakis, eds. Elias G. Mariolopoulos et al., 11-21. Dordrecht: Springer.

Cooley, William D. 1854. Claudius Ptolemy and the Nile: Or an Inquiry into That Geographer's Real Merits and Speculative Errors, His Knowledge of Eastern Africa and the Authenticity of the Mountains of the Moon. London: Parker and Son West Strand.

D’Anville, Jean-Baptiste Bourguignon. 1741. Écclaircissements géographiques sur l'ancienne Gaule: precedés d'un traité des mesures itinéraires des romains, et de la lieue gauloise. Paris. 
Datoo, Bashir Ahmed. 1971 East African Ports. In Studies in East African Geography and Development, ed. Simeon Hongo Ominde, 63-72. Oakland: University of California Press.

Dicks, David Reginald. 1960. The Geographical Fragments of Hipparchus. London: Athlone Press.

Diller, Aubrey. 1949. The Ancient Measurements of the Earth. Isis 40: 7-9.

Dinsmoor, William Bell. 1950. The Architecture of Ancient Greece: An Account of Its Historic Development. London: Batsford.

Dörpfeld, Wilhelm. 1882. Beiträge zur antiken Metrologie. Mittheilungen des Institutes in Athen: 277-290.

Dreyer, John Louis Emil. 1953. A History of Astronomy from Thales to Kepler, 2nd ed. New York: Dover Publications.

Dutka, Jacques. 1993. Eratosthenes' Measurement of the Earth Reconsidered. Archive for History of Exact Sciences 46: 55-66.

Edelstein, Ludwig, and Ian Gray Kidd. 2005. Posidonius. The Fragments, Vol. I, 2nd ed. Cambridge: Cambridge University Press.

Engels, Donald. 1985. The Length of Eratosthenes` Stade. The American Journal of Philology 106: $298-311$.

Ferrar, Michael. 2010. Eratosthenes, Hipparchus and Strabo: Geographia. The Length of the Oikoumene Measured on an Aslant Alignment. https://www.cartographyunchained.com/es1.html.

Fessler, Daniel M. T., Kevin J. Haley, and Rosni D. Lal. 2005. Sexual Dimorphism in Foot Length Proportionate to Stature. Annals of Human Biology 32 (1): 44-59.

Fiechter, Ernst Robert. 1929. Stadion (der Bau). In Paulys Realencyclopädie der classischen Altertumswissenschaft II (6), cols. 1967-1973. Stuttgart: Metzler.

Firsov, Lev V. 1972. Ob Eratosfenovom ischislenii okruzhnosti Zemli i dliny ellinisticheskogo stadija. Vestnik Drevnej Istorii 121: 154-174.

Fisher, Irene. 1975. Another Look at Eratosthenes' and Posidonius' Determination of the Earth's Circumference. Quarterly Journal of the Royal Astronomical Society 16: 152-167.

Fraser, Peter Marshall. 1972. Ptolemaic Alexandria, 3 vols. Oxford: Clarendon Press.

French, David. 1998. Pre- and Early-Roman Roads of Asia Minor. The Persian Royal Road. Iran 36: 15-43.

Geus, Klaus and Irina Tupikova. [in press]. The Black Sea in Ptolemy's Geography and (Ps.-) Arrian's Periplus Ponti Euxini: Explaining Some Differences and Errors. In Arrian's Black Sea, eds. Anca Dan et al.

Geus, Klaus, and Irina Tupikova. 2013. Von der Rheinmündung in den Finnischen Golf ... Neue Ergebnisse zur Weltkarte des Ptolemaios, zur Kenntnis der Ostsee im Altertum und zur Flottenexpedition des Tiberius im Jahre 5. n. Chr. Geographia Antiqua 22: 125-143.

Geus, Klaus, and Irina Tupikova. 2014. The Location of Novaesium: A New Interpretation of Ptolemy's Coordinates. Orbis Terrarum 12: 293-309.

Gosselin, Pascal-Francois-Joseph. 1790. Géographie des Grecs analysée; ou les systêmes d'Eratosthenes, de Strabon et de Ptolemée comparés entre eux et avec nos connoissances modernes. Paris: de Didot.

Gosselin, Pascal-Francois-Joseph. 1813. Observations générales sur la manière de considérer et d'évaluer les anciens stades itinéraires, sur les erreurs que le faux emploi de ces mesures a répandues dans le système géographique des Grecs, et sur le moyen de ramener ce système à son exactitude primitive. Paris: de l'Imprimerie impériale.

Gosselin, Pascal-Francois-Joseph. 1819. Recherches sur le principe, le bases et l'évalution des différens systèmes métriques linéaires de l'antiquité. Paris: de l'Imprimerie royale.

Gusev, Dmitri, Sergey Stafeyev, and Lydmila Filatova. 2005. Iterative Reconstruction of Ptolemy's West Africa. The $10^{\text {th }}$ International Conference on the Problems of Civilization. Moscow: RosNOU.

Hansman, John. 1981. The Measure of Hecatompylos. The Journal of the Royal Asiatic Society of Great Britain and Ireland I: 3-9.

Hecht, Konrad. 1979. Zum römischen Fuß. Abhandlungen der Braunschweigischen Wissenschaftlichen Gesellschaft, 30: 107-137.

Henneberg, Maciej, and Renata Henneberg. 1998. Biological Characteristics of the Population Based on Analysis of Skeleton Remains. In The chora of Metaponto: The Necropoleis, ed. Josef C. Carter, 504-547. Austin: University of Texas Press.

Heß, Jurgen. 2013. Die Themelioi des Claudius Ptolemaios. http://www.juergenhess.org/themen/diethemelioi-des-ptolemaios-2013. Accessed: 25 February 2018.

Hiller, Eduard. 1995. Theon (Smyrnaeus): [Expositio rerun mathematic arum ad legendum Platonem utilium]. Stutgart/Leipzig: Teubner.

Hirsch, Antoine Pierre. 2013. Ancient Egyptian Cubits-Origin and Evolution. PhD Thesis. University of Toronto, Canada. 
Hugo, Berger. 1880. Die geographischen Fragmente des Eratosthenes. Leipzig: Teubner.

Hultsch, Friedrich, ed. 1864. Heronis Alexandrini. geometricorum et stereometricorum reliquiae. Berlin: Weidmann.

Hultsch, Friedrich. 1882. Griechische und römische Metrologie. Graz: Akademische Druck- und Verlagsanstalt.

Hultsch, Friedrich. 1897. Elemente der ägyptischen Teilungsrechnung. Leipzig: Hirzel.

Ideler, Cristian Ludwig. 1826/1827. Über die Längen- und Flächenmaße der Alten. Dritter Theil. Von den Wegemassen der alten Geographie. Zweiter Abschnitt. Über die von d'Anville in die alte Geographie eingeführten Stadien. Abhandlungen der Königlichen Akademie der Wissenschaften zu Berlin: Philosophisch-Historische Klasse 1826: 1-18; 1827: 111-128.

Jansen-Winkeln, Karl. 2006. Schoinos. In Brill's New Pauly, Antiquity volumes, eds. Huber Cancik and Helmuth Schneider. Leiden/Boston: Brill.

Jomard, Edme-François. 1817. Mémoire sur le système métrique des anciens Égyptiens contenant des recherches sur leurs connoissances géométriques et sur les mesures des autres peuples de l'antiquité. Paris: De L'Imprimerie Royale.

Judeich, Walter. 1905. Topographie von Athen. München: C. H. Beck.

Kienast, Hermann. 1995. Die Wasserleitung des Eupalinos auf Samos. Deutsches Archäologisches Institut: 19.

Kleineberg, Andreas, Christian Marx, Eberhard Knobloch, and Dieter Lelgemann. 2010. Germania und die Insel Thule: die Entschlüsselung von Ptolemaios' "Atlas der Oikumene”. Darmstadt: Wissenschaftliche Buchgesellschaft.

Kleineberg, Andreas, Christian Marx, and Dieter Lelgemann. 2012. Europa in der "Geographie des Ptolemaios". Die Entschlüsselung des "Atlas der Oikumene": Zwischen Orkney, Gibraltar und den Dinariden. Darmstadt: Wissenschaftliche Buchgesellschaft.

Knapik, Joseph and Katy Reynolds. 1997. Load carriage in military operations: A review of historical, physiological, biomechanical, and medical aspects. Soldier Performance Division, Human Research and Engineering Directorate, U. S. Army Research Laboratory and U. S. Army Research Institute of Environmental Medicine. http://www.dtic.mil/cgi-bin/GetTRDoc?AD=ADA330082. Accessed 16 Feb 2018 .

Kron, Geoffrey. 2005. Anthropometry, physical anthropology, and the reconstruction of ancient heath, nutrition, and living standards. Historia 54: 68-83.

Leake, William Martin. 1839. On the stade, as a linear measure. Journal of the Royal Geographical Society of London 9: 1-25.

Lehmann-Haupt, Carl Friedrich. 1929. Stadion. In Paulys Realencyclopädie der classischen Altertumswissenschaft, ed. August Friedrich von Pauly. Stuttgart: Metzler.

Lepsius, Richard. 1866. Die altägyptische Elle und ihre Einteilung. Philologische und historische Abhandlungen der Königlichen Akademie der Wissenschaften zu Berlin, aus dem Jahre 1865. Berlin: Dümmler.

Letronne, Antoine Jean. 1851. Recherches critiques, historiques et géographiques sur les fragments D'Héron D’Alexandri, ou, du système métrique égyptiene. Paris: L'Imprimerie Nationale.

Lewis, Michael Jonathan Taunton. 2001. Surveying Instruments of Greece and Rome. Cambridge: Cambridge University Press.

Loret, Victor. 1903. L'Atour et la Dodècaschène. Sphinx 7: 1-24.

Marx, Christian. 2014. Lokalisierung von Pytheas' und Ptolemaios' Thule. Zeitschrift Für Geodäsie, Geoinformation Und Landmanagement 139: 1-7.

Marx, Christian. 2015. Analysis of the longitudinal data of Eratosthenes and Hipparchus. Mathematics and Mechanics of Complex Systems 3: 309-339.

Marx, Christian, and Andreas Kleineberg. 2012. Die Geographie des Ptolemaios: Geographike Hyphegesis Buch 3: Europa zwischen Newa, Don und Mittelmeer. Berlin: Epubli.

Meuret, Christophe. 1998. Outils mathématiques et données itineraires: reflexions sur evalution de la circonférence terrestre chez Ptolémée. In Geographica Historica, eds. Pascal Arnaud, and Patrick Counillon, 151-166. Bordeaux/Nice: Ausonius Éditions.

Miller, Konrad. 1919. Die Erdmessung im Altertum und Ihr Schicksal. Stuttgart: Strecker und Schröder.

Müllenhoff, Karl. 1870. Deutsche Altertumskunde, I. Berlin: Weidmann.

Nachtigal, Gustav. 1978. Die Eroberung des Sudans. 1869-1874. Berlin/Darmstadt/Wien: Koch.

Neugebauer, Otto. 1975. A history of ancient mathematical astronomy. Berlin: Springer.

Niebuhr, Carsten. 1973. Entdeckungen im Orient. 1761-1767. Tübingen/Basel: Erdmann. 
Oxé, August. 1926. Die römische Meile, eine griechische Schöpfung. Bonner Jahrbücher: Jahrbücher Des Vereins Von Altertumsfreunden in Rheinlande 131: 213-244.

Oxé, August. 1963. Die Masstafel des Julianus von Askalon. Rheinisches Museum für Philologie 106: 264-286.

Panchenko, Dmitri. 2016. The sixth-century Samian foot of $26.25 \mathrm{~cm}$ and evolution of the greek linear measure. Hyperboreus 22 (2): 185-191.

Petrie, William Matthew Flinders. 1883. The pyramids and temples of Gizeh. London: Field and Tuer.

Politis, Nikolaos G. 1896. Das Panathenäische Stadion/The Panathenaic Stadion. In Die Olympischen Spiele 776 v. Chr. - 1896 n. Chr., 1. Theil: Die Olympischen Spiele im Altertum, eds. Spyridon P. Lambros, and Nikolaos G. Politis, 31-49. Athen: Beck.

Pothecary, Sarah. 1995. Strabo, Polybios, and the stade. Phoenix 49 (1): 49-67.

Prell, Heinrich. 1957. Die Stadienmasse des Klassischen Altertums in ihren Wechselseitigen Beziehungen. Wissenschaftliche Zeitschrift Der Technischen Hochschule Dresden 6: 549-563.

Priskin, Gyula. 2004. Reconstructing the length and subdivision of the iteru from late Egyptian and GraecoRoman texts. Discussions in Egyptology 60: 57-71.

Rabe, Hugo. 1906. Scholia in Lucianum. Leipzig: Teubner.

Radt, Stefan. 2002. Noch einmal zu: Kleine Schriften von Stefan Radt zu seinem 75. Geburtsag. In Mnemosyne, Bibliotheca Classica Batava Supplementum 235, eds. Annette Harder et al. Leiden: Brill.

Rawlins, Dennis. 1982. The Eratosthenes-Strabo nile map. is it the earliest surviving instance of spherical cartography? Did it supply the 5000 stades arc for Eratosthenes' experiment? Archive for History of Exact Sciences 26: 211-219.

Reinecke, Walter-Friedrich. 2014. Gedanken und Materialien zur Frühgeschichte der Mathematik. InternetBeiträge zur Ägyptologie und Sudanarchäologie XVI. Berlin/London: Golden House.

Rennel, James. 1800. The geographical system of Herodotus. London: Bulmer.

Rinner, Elisabeth. 2013. Zur Genese der Ortskoordinaten Kleinasiens in der Geographie des Klaudios Ptolemaios. Bern: Bern Studies in the History and Philosophy of Science.

Rohren, Brenda. 2009. Estimation of stature from foot and shoe length: applications in forensic science. Nebraska: Nebraska Wesleyan University.

Roller, Duane W. 2014. The “Geography” of Strabo. The English Translation with Introduction and Notes. Cambridge: Cambridge University Press.

Roller, Duane W. 2010. Eratosthenes' “Geography”: Fragments collected and translated with commentary and additional material. Princeton/Oxford: Princeton University Press.

Romano, David Gilman. 1993. Athletics and mathematics in archaic Corinth: The origins of the greek stadion. Philadelphia: American Philosophical Society.

Rosen, Gustav. 1865. Guarmani's Reise nach dem Negd. Ein Beitrag zur geographischen Kenntniss Arabiens. Zeitschrift Für Allgemeine Erdkunde 18: 201-218.

Russo, Lucio. 2013. Ptolemy's longitudes and Eratosthenes' measurement of the Earth's circumference. Mathematics and Mechanics of Complex Systems 1 (1): 67-79.

Russo, Lucio. 2018. Far-reaching hellenistic geographical knowledge hidden in Ptolemy's data. Mathematics and Mechanics of Complex Systems 6 (3): 181-200.

Schäfer, Heinrich. 1902. Ein Bruchstück altägyptischer Annalen. Abhandlungen der Königlichen Preussische Akademie der Wissenschaften. Philosophische und Historische Abhandlungen. Berlin: Verlag der Königlichen Akademie der Wissenschaften.

Schlott-Schwab, Adelheid. 1981. Die Ausmaßen Ägyptens nach altägyptischen Texten. Wiesbaden: Harrasowitz.

Schwartz, Adam. 2013. Large weapons, small Greeks: The practical limitations of hoplite weapons and equipment. In Men of Bronze: Hoplite Warfare in Ancient Greece, ed. Donald Kagan and Gregory F. Viggiano, 157-175. Princeton: Princeton University Press.

Schweinfurt, Georg. 1872. Ergebnisse einer Reise nach Dar-Fertit von D. G. Schweinfurth, Januar bis Februar 1871. Mitteilungen über Erforschungen auf dem Gesamtgebiete der Geographie 18: 281-295. Gotta: Petermann.

Seland, Eivind Heldaas. 2020. Coastal and high-sea passages in ancient Red Sea navigation: Combining GIS with common-sense geography. In Methods and models in ancient history. Studies in honor of Jørgen Christian Meyer, eds. Ingvar Maele, Per Bjarne Ravna, and Eivind Heldaas Seland, 99-110. Athens: Norwegian Institute at Athens. 
Senigalliesi, Dino. 1961. Metrological examination of some cubits preserved in the Egyptian Museum of Turin. La Rivista RIV 11: 23-52.

Shcheglov, Dmitry A. 2016a. The accuracy of ancient cartography reassessed: The longitude error in Ptolemy's cartography. Isis 107: 687-706.

Shcheglov, Dmitry A. 2016b. The error in longitude in Ptolemy's "Geography." The Cartographic Journal 53 (1): 3-14.

Shcheglov, Dmitry A. 2018. The so-called 'itinerary stade' and the accuracy of Eratosthenes' measurement of the Earth. Klio 100 (1): 153-177.

Sidebotham, Steven Edward. 1986. Roman economic policy in the Erythra Thalassa 30 B. C.-A.D. 217. Leiden: Brill.

Sidebotham, Steven Edward. 1991. Ports of the Red Sea and the Arabia-India Trade. In Rome and India: The ancient sea trade, ed. Vimala Begley and Ricard D. De Puma, 12-38. Madison: University of Wisconsin Press.

Sidebotham, Steven Edward. 2011. Berenike and the Ancient Maritime Spice Route. Los Angeles: University of California Press.

Stückelberger, Alfred. 1988. Einführung in die antiken Naturwissenschaften. Darmstadt: Academic in Wissenschaftliche Buchgesellschaft.

Stückelberger, Alfred. 2009. Masse und Messungen. In Klaudios Ptolemaios. Handbuch der Geographie. Ergänzungsband mit einer Edition des Kanons bedeutender Städte, eds. Alfred Stückelberger, and Florian Mittenhuber, 218-244. Basel: Schwabe Verlag.

Stückelberger, Alfred, and Graßhoff Gerd, eds. 2006. Klaudios Ptolemaios. Handbuch der Geographie, Griechisch-Deutsch, Einleitung, Text und Übersetzung. Basel: Schwabe Verlag.

Tannery, Paul. 1893. Recherces sur l'histoire de l'astronomie ancienne. Paris: Hachette Livre.

Taylor, Eva Germaine Rimington. 1971. The Haven-finding Art: A history of navigation from Odysseus to Captain Cook. London: Cambridge University Press and The Institute of Navigation.

Thonemann, Peter. 2003. Hellenistic inscriptions from Lydia. Epigraphica Anatolica 36: 95-108.

Tozer, Henry Fanshawe. 1897. A history of ancient geography. Cambridge: Cambridge University Press.

Tucker, Aviezer, ed. 2008. A Companion to the Philosophy of History and Historiography. Chichester: John Wiley and Sons.

Tupikova, Irina, and Klaus Geus. 2013. The Circumference of the Earth and Ptolemy's World Map. Max Planck Institute for the History of Science, Preprint 439. http://www.mpiwg-berlin.mpg.de/Preprints/ P439.PDF. Accessed 25 Feb 2018.

Tupikova, Irina, Matthias Schemmel, and Klaus Geus. 2014. Travelling along the Silk Road: A new interpretation of Ptolemy's coordinates. Max Planck Institute for the History of Science, Preprint 465. http://www.mpiwg-berlin.mpg.de/Preprints/P465.PDF. Accessed 25 Feb 2018.

Tupikova, Irina. 2014. Ptolemy' circumference of the Earth. Max Planck Institute for the History of Science, Preprint 464. http://www.mpiwg-berlin.mpg.de/Preprints/P464.PDF Accessed 25 Feb 2018.

Tupikova, Irina. 2018. Eratosthenes' measurements of the Earth: Astronomical and geographical solutions. Orbis Terrarum 16: 221-254.

Tupikova, Irina, and Michael Soffel. 2012. Modelling ancient sundials: Ancient and modern errors. In Productive errors: Scientific concepts in antiquity, ed. Klaus Geus and Mark Geller, 93-114. Berlin: Max Planck Institute for the History of Science.

Viedebantt, Oskar. 1915. Eratosthenes, Hipparchos, Poseidonios: Ein Beitrag zur Geschichte des Erdmessungsproblems im Altertum. Klio 14: 207-256.

Zakrsewski, Sonia. 2003. Variation in ancient Egyptian stature and body proportions. American Journal of Physical Anthropology 121 (3): 219-229.

Ziller, Ernst. 1870. Ausgrabung am Panathenaischen Stadion auf Kosten S.H. des Königs von Griechenland. Zeitschrift Für Bauwesen 20: 485-492.

Publisher's Note Springer Nature remains neutral with regard to jurisdictional claims in published maps and institutional affiliations. 